NASA/TM-1999-107249, Chapter 7

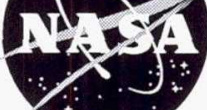

\title{
Aerospace Mechanisms and Tribology Technology: Case Studies
}

Kazuhisa Miyoshi

Glenn Research Center, Cleveland, Ohio 
The NASA STI Program Office ... in Profile

Since its founding, NASA has been dedicated to the advancement of aeronautics and space science. The NASA Scientific and Technical Information (STI) Program Office plays a key part in helping NASA maintain this important role.

The NASA STI Program Office is operated by Langley Research Center, the Lead Center for NASA's scientific and technical information. The NASA STI Program Office provides access to the NASA STI Database, the largest collection of aeronautical and space science STI in the world. The Program Office is also NASA's institutional mechanism for disseminating the results of its research and development activities. These results are published by NASA in the NASA STI Report Series, which includes the following report types:

- TECHNICAL PUBLICATION. Reports of completed research or a major significant phase of research that present the results of NASA programs and include extensive data or theoretical analysis. Includes compilations of significant scientific and technical data and information deemed to be of continuing reference value. NASA's counterpart of peerreviewed formal professional papers but has less stringent limitations on manuscript length and extent of graphic presentations.

- TECHNICAL MEMORANDUM. Scientific and technical findings that are preliminary or of specialized interest, e.g., quick release reports, working papers, and bibliographies that contain minimal annotation. Does not contain extensive analysis.

- CONTRACTOR REPORT. Scientific and technical findings by NASA-sponsored contractors and grantees.
- CONFERENCE PUBLICATION. Collected papers from scientific and technical conferences, symposia, seminars, or other meetings sponsored or cosponsored by NASA.

- SPECIAL PUBLICATION. Scientific, technical, or historical information from NASA programs, projects, and missions, often concerned with subjects having substantial public interest.

- TECHNICAL TRANSLATION. Englishlanguage translations of foreign scientific and technical material pertinent to NASA's mission.

Specialized services that complement the STI Program Office's diverse offerings include creating custom thesauri, building customized data bases, organizing and publishing research results ... even providing videos.

For more information about the NASA STI Program Office, see the following:

- Access the NASA STI Program Home Page at http://www.sti.nasa.gov

- E-mail your question via the Internet to help@sti.nasa.gov

- Fax your question to the NASA Access Help Desk at (301) 621-0134

- Telephone the NASA Access Help Desk at (301) 621-0390

- Write to:

NASA Access Help Desk

NASA Center for AeroSpace Information 7121 Standard Drive

Hanover, MD 21076 
NASA/TM-1999-107249, Chapter 7

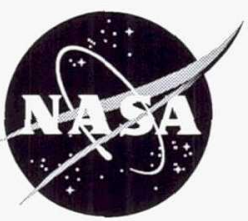

\section{Aerospace Mechanisms and Tribology Technology: Case Studies}

Kazuhisa Miyoshi

Glenn Research Center, Cleveland, Ohio

National Aeronautics and

Space Administration

Glenn Research Center 
Available from

NASA Center for Aerospace Information 7121 Standard Drive

Hanover, MD 21076

Price Code: A03
National Technical Information Service 5287 Port Royal Road Springfield, VA 22100 Price Code: A03 


\section{Chapter 7}

\section{Aerospace Mechanisms and Tribology Technology: Case Studies}

\subsection{Introduction}

In the United States space program alone a large number of spacecraft failures and anomalies have occurred (e.g., Galileo and Hubble). In addition, more demanding requirements have been causing failures or anomalies to occur during the qualification testing of future satellites and space platform mechanisms even before they are launched (e.g., GOES-NEXT, CERES, International Space Station beta joint gimbals [7.1]). In space programs throughout the world a much greater number of failures and anomalies of space mechanisms have occurred.

In the operation of space mechanisms functional reliability is, of course, vital. Even a small tribological failure can lead to catastrophic results in a spacecraft [7.2]. In this chapter an attempt is made to review aspects of real problems related to vacuum or space tribology technology and dry solid film lubrication as case studies:

1. Case study A: Galileo spacecraft's high-gain antenna deployment anomaly

2. Case study B: Space shuttle orbiter's quad check valve failures

To understand the adhesion, friction, wear, and lubrication situation in each case study, the nature of the problem is analyzed, the tribological properties are examined, the range of potential solutions is analyzed, and recommendations are made.

NASA/TM-1999-107249, Chapter 7 


\subsection{Case Study A: Galileo Spacecraft's High-Gain Antenna Deployment Anomaly}

\subsubsection{Galileo's Partially Unfurled High-Gain Antenna: The Anomaly at 37 Million Miles}

The Galileo spacecraft and its inertial upper stage booster rocket were deployed from the space shuttle Atlantis on October 18, 1989. Shortly thereafter the booster rocket fired and separated, sending Galileo on its six-year journey to the planet Jupiter.

Figure 7.1 shows the locations of many of Galileo's main structural and scientific components. Galileo is a spin-stabilized spacecraft and has three Earth-to-spacecraft communications antennas for commanding and returning spacecraft telemetry. Two of the antennas are low gain and the third is high gain. The umbrella-like highgain antenna is located at the top of the spacecraft and is $4.8 \mathrm{~m}(16 \mathrm{ft})$ in diameter. It was designed to transmit data back to Earth at up to 134000 bits per second (the equivalent of about one television picture each minute). The antenna, which is made of gold-plated metal mesh, was stowed behind a Sun shield at launch to avoid heat damage from the direct Sun while the spacecraft flew close to the Sun.

On April 11, 1991, when the Sun-to-spacecraft distance was large enough to present no thermal danger to the antenna, the Galileo spacecraft began to deploy its high-gain antenna under computer-sequence control. Within minutes Galileo's flight team, watching spacecraft telemetry 37 million miles away on Earth, could

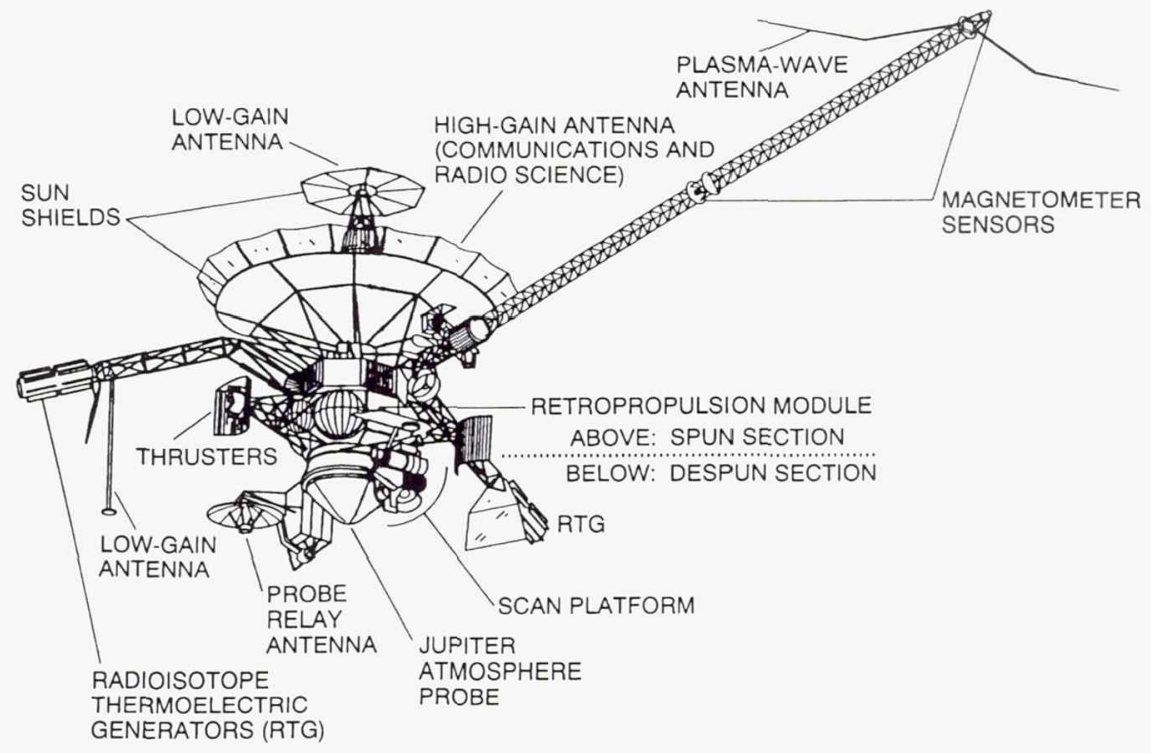

Figure 7.1.-Galileo spacecraft configuration.

NASA/TM-1999-107249, Chapter 7 
see that something was wrong: The motors had stalled and something had stuck. The antenna, the $4.8-\mathrm{m}$ mesh paraboloid stretched over 18 umbrella-like ribs, had opened only part way.

Galileo has been in orbit around Jupiter and its moons for the past three years and is operating as it processes and sends science data to Earth with one of the low-gain antennas. (The low-gain and high-gain antennas are part of the same assembly and face in the same direction.) Its primary mission ended in December 1997, and the spacecraft is currently in the midst of a two-year extension known as Galileo Europa Mission. For additional details on Galileo's high-gain antenna deployment anomaly, see references 7.3 to 7.5 .

\subsubsection{Anomaly Investigation}

The anomaly investigation involved more than 100 people in testing, simulation, analysis, consultation, and review. After a thorough analysis of the telemetry and then ground testing and analysis, the investigation attributed the problem to the sticking of three of the antenna's 18 ribs in the stowed (or closed) position due to high friction between their standoff pins and their sockets (Fig. 7.2). The other ribs are partially open (Fig. 7.3). The anomaly review team is confident that nothing is

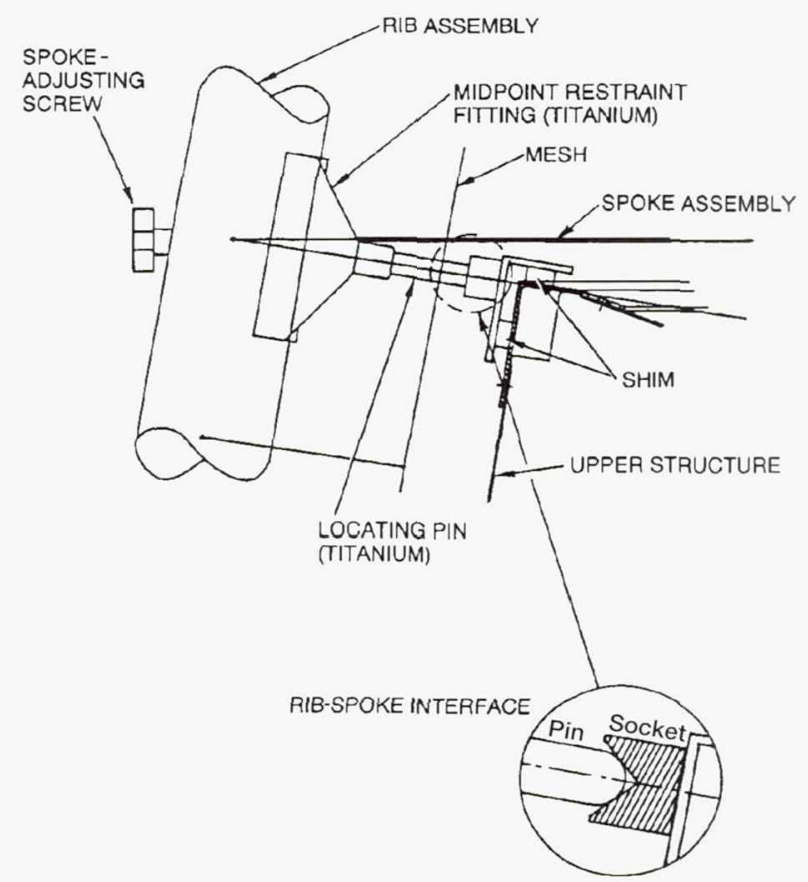

Figure 7.2.-Rib-spoke interface on Galileo spacecraft high-gain antenna.

NASA/TM-1999-107249, Chapter 7 


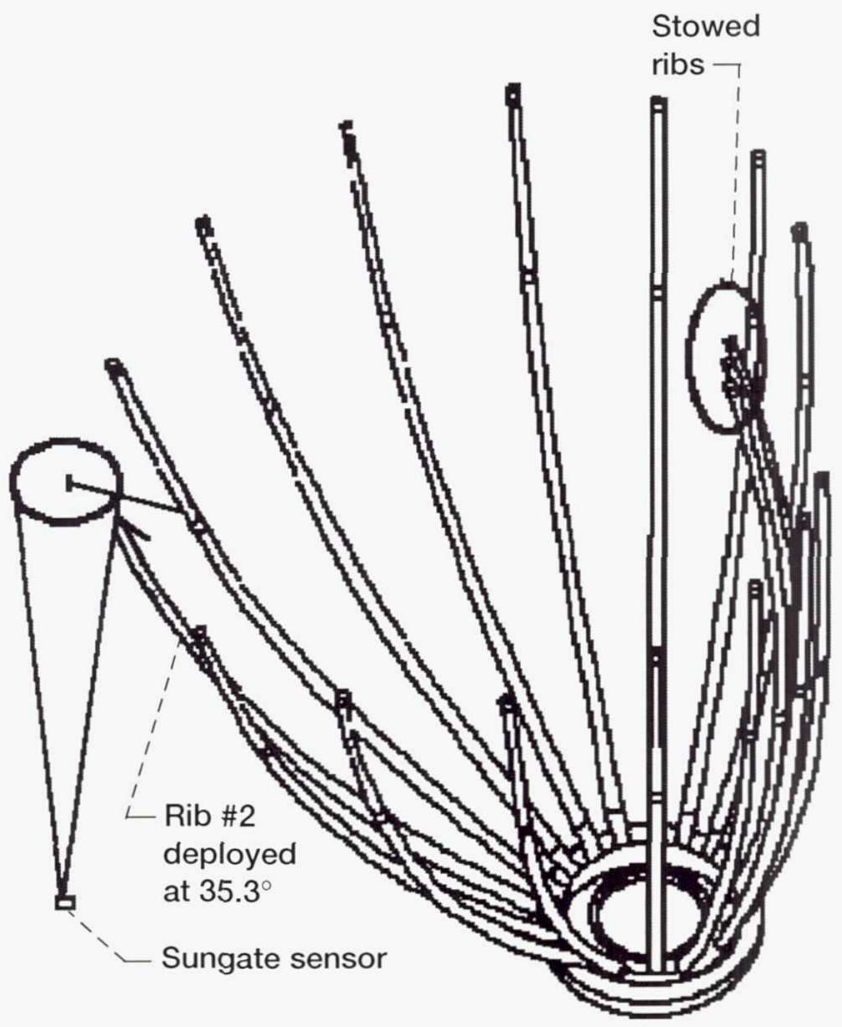

Figure 7.3.-Ribs of Galileo high-gain antenna, showing three stuck in stowed position.

broken and that three adjacent antenna ribs are stuck to the central tower by friction in their paired standoff pins, which are likely misaligned enough that one pin binds the upper side of its socket and its mate the lower (Fig. 7.4).

This attribution led, in turn, to the hypothesis that repeated thermal cycling, warm-cool-warm-cool, could walk the paired pins out, freeing the ribs. The spacecraft was maneuvered to warm the high-gain antenna by solar heating and to cool it in the shade. This warming and cooling, however, did not release the stuck ribs. In addition to thermal cycling other ideas were developed for loosening the stuck ribs, but the antenna still remains stuck. After a multiyear campaign to try to free the stuck ribs, lasting until 1996, there is no longer any significant prospect of deploying the antenna.

Although freeing and using the high-gain antenna have not been ruled out, another option has been taken. By using the low-gain antenna along with advanced data-compression processing techniques in the spacecraft computers and advanced hardware and techniques on the ground, a significant fraction of the total planned Jupiter science data has been captured. 


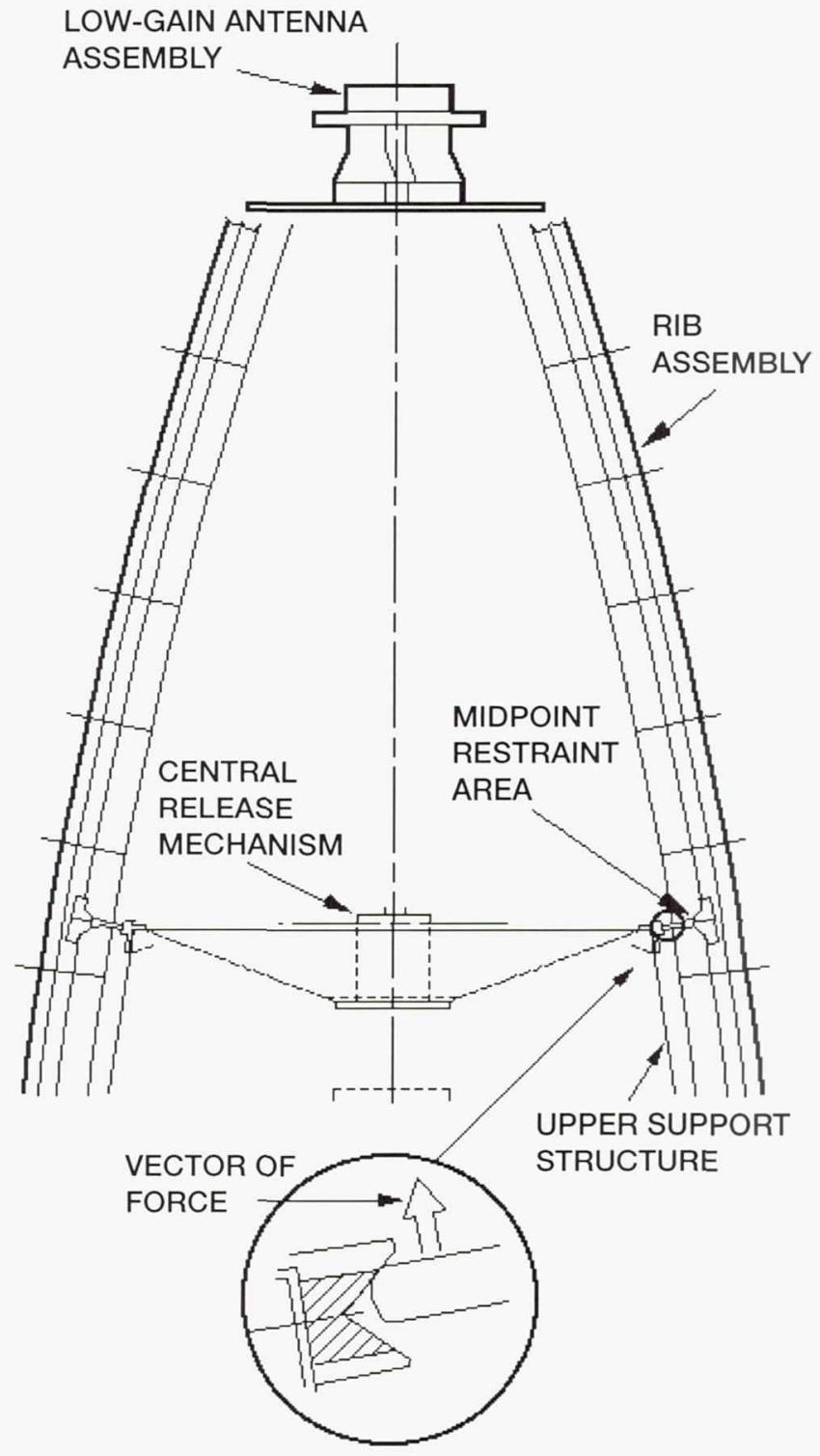

Figure 7.4.-Standoff pin misaligned in its socket. 


\subsubsection{Investigation of Adhesion, Friction, Wear, and Cold Welding}

\subsubsection{Experimental Conditions}

To find the causes of the stuck antenna ribs in the Galileo spacecraft, sliding friction experiments were conducted using a tribometer (vacuum friction apparatus) with a pin-on-disk configuration in vacuum (space-like) environments and in air [7.6]. The materials, loads, and environments (Table 7.1) were chosen to simulate the conditions that the rib-spoke interface of the antenna's alignment pins may have experienced.

The contacting surface of the pin specimens was hemispherical with a radius of curvature of $0.5 \mathrm{~mm}$. Two types of pin specimen were examined: coated titanium, $6 \mathrm{wt} \%$ aluminum, $4 \mathrm{wt} \%$ vanadium (Ti-6Al-4V) pins and bare Ti-6Al-4V pins. The surfaces of the coated Ti-6Al-4V pins had first been coated with an electrolytically converted hard coating of titanium by using an all-alkaline bath maintained at room temperature. Then the pin surfaces were coated with an inorganic, bonded dry-film lubricant ( $25 \mathrm{~mm}$ thick) that contained a molybdenum disulfide pigment. The coatings produced antigalling and wear resistance properties on the Ti-6Al-4V pin surfaces (Fig. 7.5). Because the lubricant and the coating may have failed on the spacecraft, a bare pin-rib system was also examined as a reference.

The contacting surface of the disk specimens was flat, $25 \mu \mathrm{m}$ in diameter, and $5 \mathrm{~mm}$ thick. The disk specimens were uncoated, bare high-nickel-content superalloy (Inconel 718). The average surface roughness of the disks was $34 \mathrm{~nm}$ root mean square

TABLE 7.1-EXPERIMENTS

(a) Materials

\begin{tabular}{|c|l|l|l|l|c|}
\hline \multicolumn{2}{|c|}{ Contacting materials } & \multicolumn{2}{c|}{ Pretreatment } & \multicolumn{2}{c|}{ Dry-film lubricant } \\
\hline Pin & \multicolumn{1}{|c|}{ Disk } & \multicolumn{1}{c|}{ Pin } & Disk & \multicolumn{1}{c|}{ Pin } & Disk \\
\hline Ti-6Al-4V & $\begin{array}{l}\text { High-nickel-content } \\
\text { superalloy }\end{array}$ & Bare & Bare & None & None \\
\hline Ti-6Al-4V & $\begin{array}{l}\text { High-nickel-content } \\
\text { superalloy }\end{array}$ & $\begin{array}{l}\text { Electrolytically } \\
\text { converted hard } \\
\text { Ti coating }\end{array}$ & Bare & $\begin{array}{l}\text { Bonded MoS } \\
\text { dry-film } \\
\text { lubricant }\end{array}$ & None \\
\hline
\end{tabular}

(b) Conditions

\begin{tabular}{|c|}
\hline $\begin{array}{l}A \\
V\end{array}$ \\
\hline $\begin{array}{l}\text { on, wt\% (maximum unless shown as rar } \\
\mathrm{Cr}, 17-21 ; \mathrm{Fe}, 12-23 ; \mathrm{Nb}+\mathrm{Ta}, 4.75-5 . \\
\text {; Co, } 1 ; \mathrm{Ti}, 0.65-1.15 ; \mathrm{Al}, 0.2-0.8 ; \mathrm{Si}, 0 \\
\mathrm{Cu}, 0.3 ; \mathrm{C}, 0.08 ; \mathrm{S}, 0.015 ; \mathrm{P}, 0.015 ; \mathrm{B}, 0 .\end{array}$ \\
\hline
\end{tabular}

NASA/TM-1999-107249, Chapter 7 


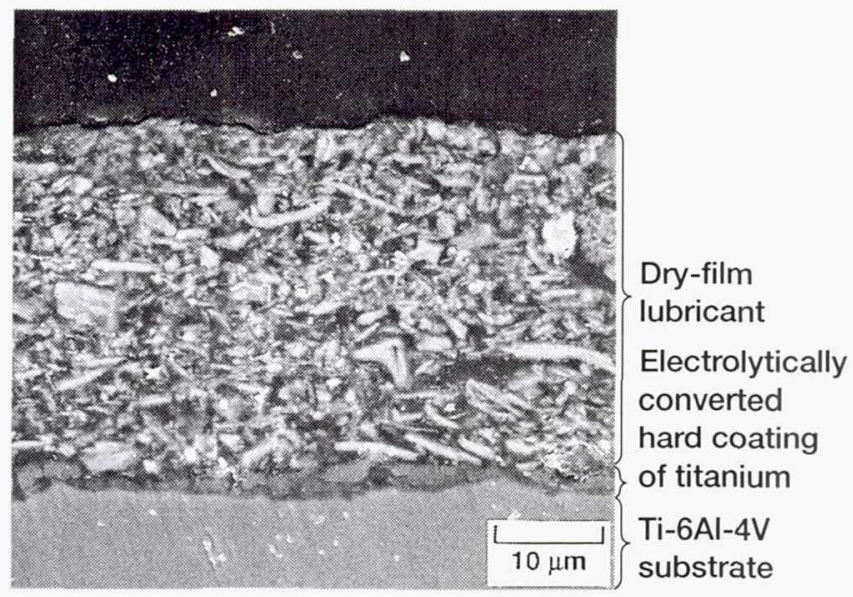

Figure 7.5.-Tapered cross section of dry-film-lubricated $\mathrm{Ti}-6 \mathrm{Al}-4 \mathrm{~V}$ pin at angle of $45^{\circ}$.

\subsubsection{Sliding Friction in Vacuum Environment}

Effect of dry-film lubricant.-The coefficient of friction for the dry-filmlubricated $\mathrm{Ti}-6 \mathrm{Al}-4 \mathrm{~V}$ in contact with the bare high-nickel-content superalloy started at 0.23 but rapidly decreased and reached an equilibrium value of about 0.04 (Fig. 7.6(a)). It remained constant for a long period of time. The friction trace fluctuated slightly with no evidence of stick-slip behavior. The sliding action finally caused the coefficient of friction to rapidly increase at 172370 passes. Wear damage (i.e., local removal of the dry-film lubricant and consequent exposure of the substrate surface), which will be discussed later, caused the high friction at this stage.

The coefficient of friction for the unlubricated, bare Ti-6Al-4V in contact with the bare high-nickel-content superalloy started at 0.31. The friction force traces for the first few sliding passes were characterized by random fluctuation, with only occasional evidence of stick-slip behavior. The presence of oxides and contaminants on the surfaces of the bare Ti-6Al-4V pin and the bare high-nickel-content superalloy disk contributed to the low initial coefficient of friction (0.31). Stick-slip behavior became dominant after a few sliding passes. The coefficient of friction rapidly increased with an increase in the number of passes. Also, the higher the number of passes, the greater was the stick-slip behavior. At approximately 10 passes and above the coefficient of friction reached an equilibrium value of approximately 1.1 and remained constant for a long period of time (Fig. 7.6(b)). The traces for 10 passes and above are primarily characterized by a continuous, marked stick-slip behavior. This type of friction is anticipated where strong metallic interactions, particularly adhesion, occur at the interface when the oxides and contaminants have been removed from the alloy surfaces by sliding action.

NASA/TM-1999-107249, Chapter 7 

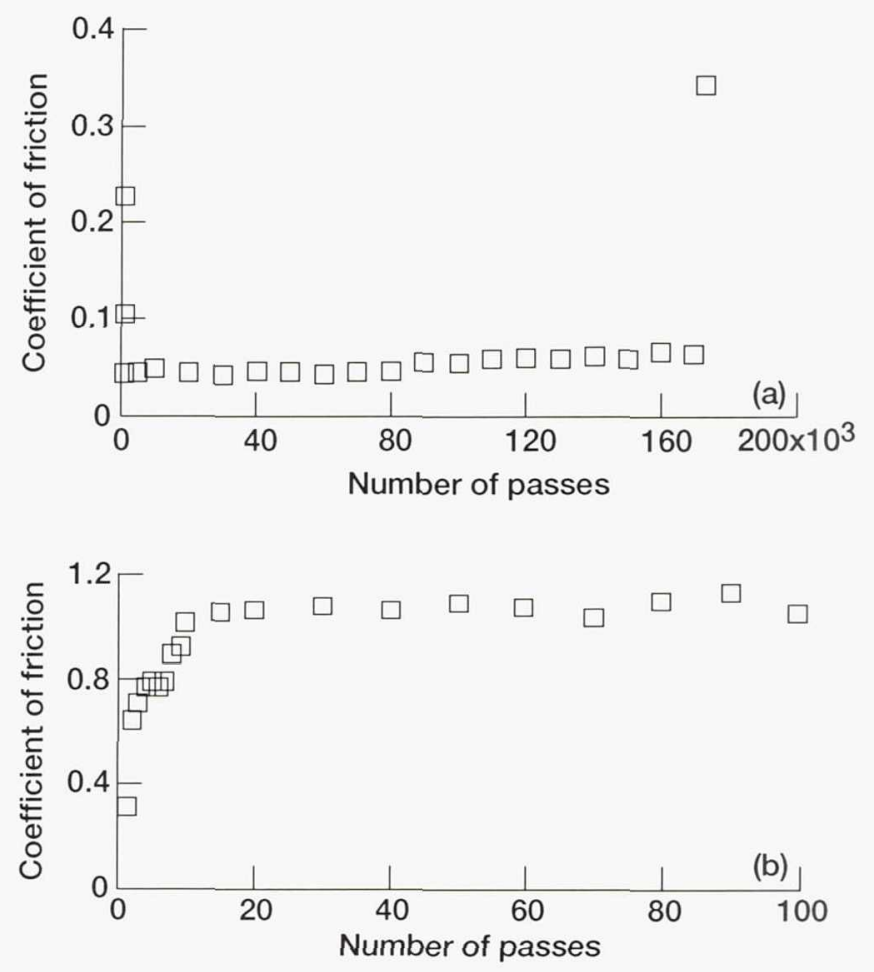

Figure 7.6.-Coefficients of friction for dry-film-lubricated and unlubricated Ti-6Al-4V pins sliding against highnickel-content superalloy disks as function of number of passes in vacuum. (a) Dry-film-lubricated pin at $8.5-\mathrm{N}$ load. (b) Unlubricated pin at 4-N load.

Comparing Figs. 7.6(a) and (b) shows that the adhesion and friction in the equilibrium conditions were less for dry-film-lubricated Ti-6Al-4V than for unlubricated, bare Ti-6Al-4V by a factor of 28 . Thus, the dry-film lubricant on the Ti-6Al-4V pin surface was effective and greatly reduced adhesion and friction.

Self-healing of dry-film lubricant.-At 172370 passes of sliding contact in vacuum (Fig. 7.6(a)) the sliding motion was stopped because of the high friction ( 0.36 or greater) caused by the wear damage. After holding the conditions for approximately $18 \mathrm{hr}$ the sliding was restarted. The result is presented in Fig. 7.7(a). The coefficient of friction after rerun became much lower than 0.36 . Further, the coefficient of friction generally decreased to about 0.05 with increasing number of passes. This result suggests that the wear damage in vacuum, which caused high friction at 172370 passes, can self-heal when rerun in vacuum.

NASA/TM-1999-107249, Chapter 7 

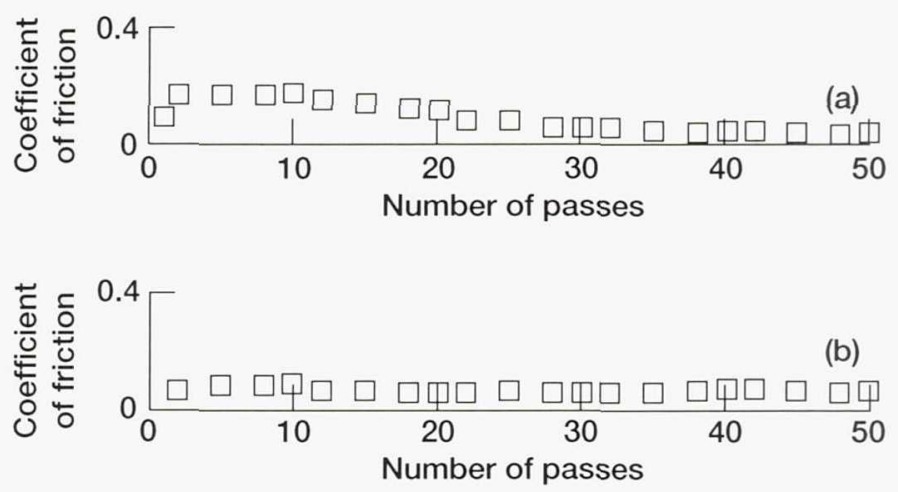

Figure 7.7.-Coefficients of friction for surfaces previously worn in vacuum of dry-film-lubricated Ti-6Al-4V pin sliding against high-nickel-content superalloy disk as function of number of passes when rerun in vacuum. (a) Load, $8.5 \mathrm{~N}$; rotating speed, $40 \mathrm{rpm}$. (b) Load, $2.5 \mathrm{~N}$; rotating speed, $1 \mathrm{rpm}$.

After 50 passes of sliding contact in the rerun process the sliding motion was stopped and the load was decreased from $8.5 \mathrm{~N}$ to $2.5 \mathrm{~N}$. Contact was maintained for $30 \mathrm{~s}$ and then sliding was begun at the new load. Decreasing the load from $8.5 \mathrm{~N}$ to $2.5 \mathrm{~N}$ did not affect the coefficient of friction, as shown in Fig. 7.7(b).

\subsubsection{Weakness of $\mathrm{MoS}_{2}$ Dry-Film Lubricant in Air}

Sliding friction in air.- In air the coefficient of friction for the molybdenum disulfide $\left(\mathrm{MoS}_{2}\right)$ dry-film-lubricated Ti-6Al-4V pin sliding on the high-nickelcontent superalloy disk started high (approximately 0.30 ) in the first 23 passes but decreased and reached an equilibrium value of about 0.14 (Fig. 7.8). Continued sliding caused the coefficient of friction to increase at 270 passes. When the coefficient of friction reached an equilibrium value of about 0.32 , the experiment was stopped.

When compared with the coefficients of friction obtained in vacuum (Fig. 7.6(a)), the coefficients of friction obtained in air (Fig. 7.8) were much higher. The coefficient of friction for the dry-film lubricant in vacuum was one-third of the value in air. Further, the endurance life of the dry-film lubricant in vacuum (the number of passes before the onset of a marked increase in friction) was about three orders of magnitude longer than that in air.

NASA/TM-1999-107249, Chapter 7 


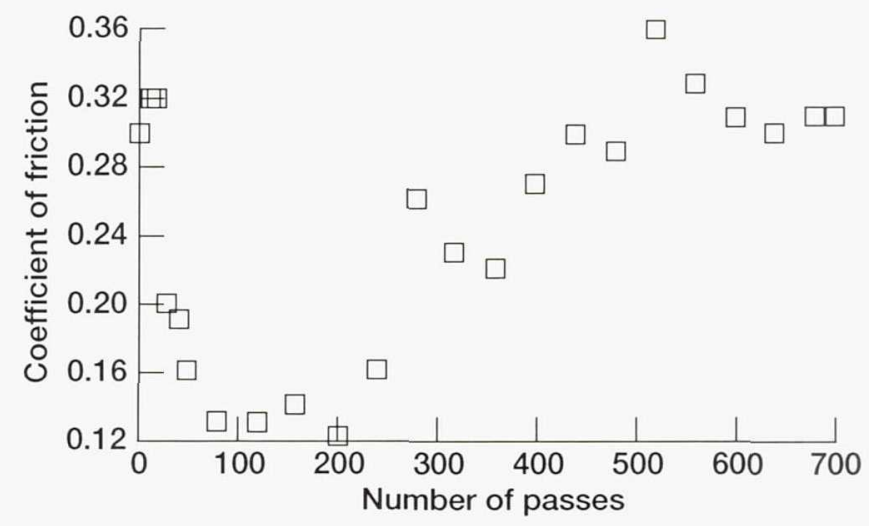

Figure 7.8.-Coefficients of friction for dry-film-lubricated Ti-6Al-4V pin sliding against high-nickel-content superalloy disk at $8.5 \mathrm{~N}$ in humid air as function of number of passes.

Seizure when rerun in vacuum.-After 700 passes in air (Fig. 7.8) the worn surfaces were at rest, and loose, large wear particles on the disk surface had been blown off. Then the vacuum chamber was evacuated to $10^{-7} \mathrm{~Pa}$. After approximately $18 \mathrm{hr}$ in contact the sliding motion was restarted. The coefficients of friction (Fig. 7.9(a)) for the pin and disk previously worn in humid air were much higher than those (Fig. 7.7(a)) for the pin and disk previously worn in vacuum. Galling increased the coefficient of friction to 0.6 .

After 50 passes of sliding contact in the rerun process the sliding motion was stopped and the load was decreased from $8.5 \mathrm{~N}$ to $2.5 \mathrm{~N}$. Contact was maintained for $30 \mathrm{~s}$ and then sliding was begun at the new load. The coefficient of friction continued to increase with increasing number of passes, as shown in Fig. 7.9(b). Seizure between the pin and disk can occur when the dry-film lubricant has sustained wear damage (i.e., local removal of the dry-film lubricant and exposure of the substrate). Galling increased the coefficient of friction to 1.4.

\subsubsection{Wear Damage}

Contact between unlubricated Ti-6Al-4V pin and high-nickel-content superalloy disk.-Figures 7.10 to 7.13 present scanning electron microscopy (SEM) photomicrographs and energy dispersion x-ray analysis (EDX) spectra of the wear damage produced on the unlubricated Ti-6Al-4V pin and on the high-nickel-content superalloy disk after 100 passes at a load of $2.5 \mathrm{~N}$. Substantial plastic deformation occurred on the unlubricated Ti-6Al-4V pin (Fig. 7.10). Large wear debris particles formed by plastic deformation and ductile fracture of the pin are present around the

NASA/TM-1999-107249, Chapter 7 

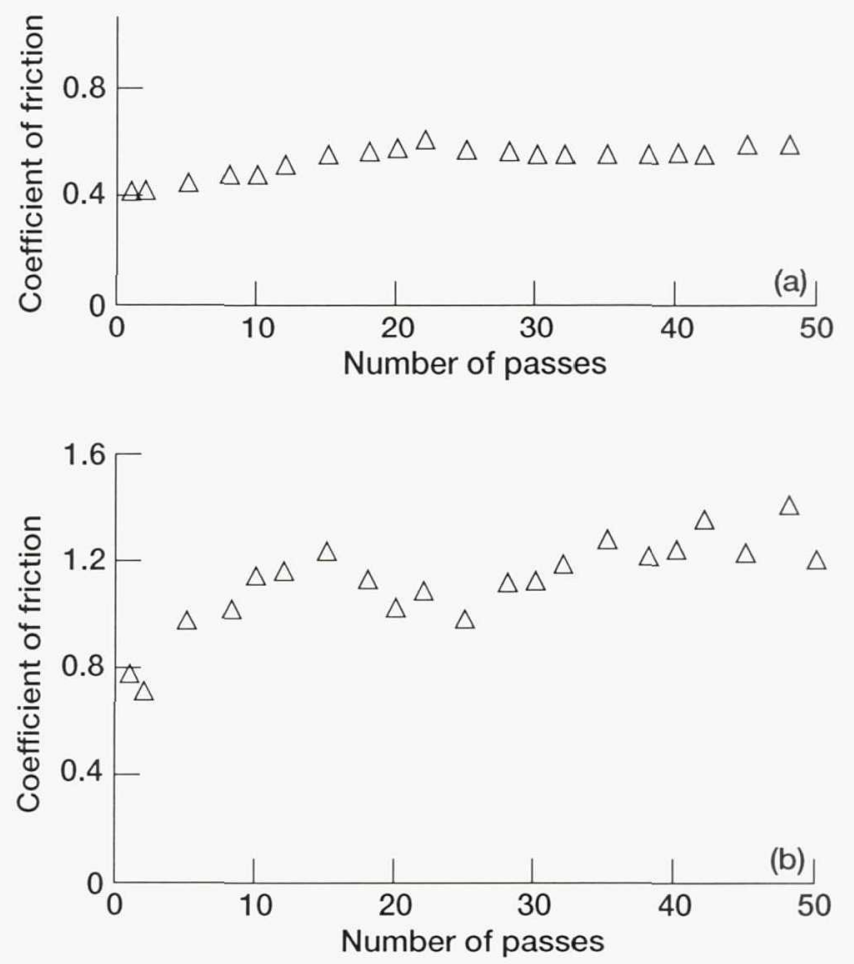

Figure 7.9.-Coefficients of friction for surfaces previously worn in humid air of dry-film-lubricated Ti-6Al-4V pin sliding against high-nickel-content superalloy disk as function of number of passes when rerun in vacuum. (a) Load, $8.5 \mathrm{~N}$; rotating speed, $40 \mathrm{rpm}$. (b) Load, $2.5 \mathrm{~N}$; rotating speed, $1 \mathrm{rpm}$.

NASA/TM-1999-107249, Chapter 7 


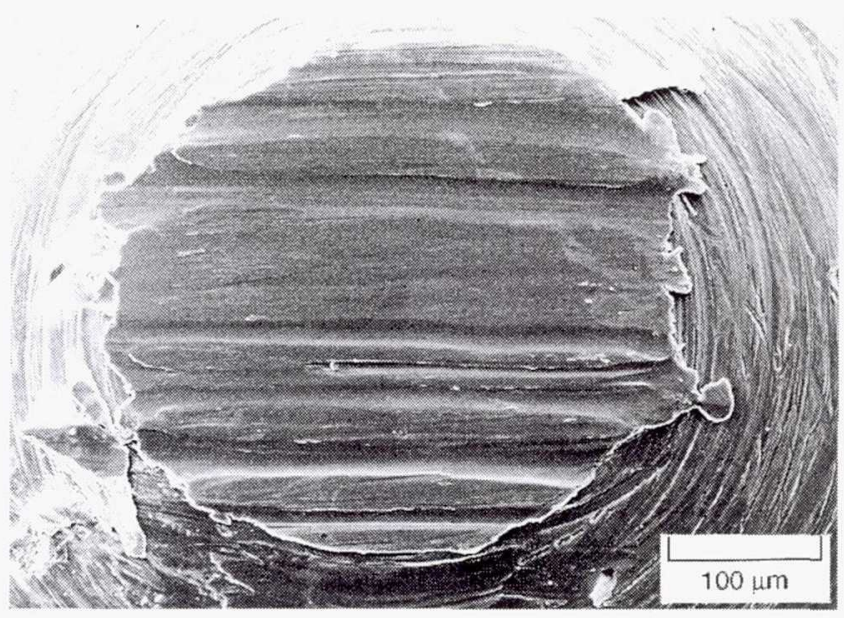

Figure 7.10.-Wear scar on unlubricated Ti-6Al-4V pin after sliding against high-nickel-content superalloy disk at $2.5 \mathrm{~N}$ in vacuum.

wear scar. Also present on the wear scar are plastically deformed grooves and clogged wear debris. Closer SEM examination and EDX analysis of the wear debris showed it to be composed primarily of elements from the Ti-6Al-4V pin (Fig. 7.11) and of small amounts of chromium, iron, and nickel from the disk.

Figures 7.12 and 7.13 show the Ti- $6 \mathrm{Al}-4 \mathrm{~V}$ patches on the wear track of the highnickel-content superalloy disk. The transfer patches occupied a large area fraction of the overall wear track. Thus, severe damage, often called scuffing, scoring, or galling, occurred in the unlubricated contact between the Ti-6Al-4V and the highnickel-content superalloy in vacuum [7.3-7.5].

Contact between dry-film-lubricated Ti-6Al-4V pin and high-nickel-content superalloy disk worn in vacuum and rerun in vacuum. - SEM photomicrographs of the worn surfaces of the dry-film-lubricated Ti-6Al-4V pin sliding against the high-nickel-content superalloy disk in vacuum and then rerun in vacuum show surface smearing, tearing, and spalling of the dry-film lubricant (Figs. 7.14 to 7.17). The wear damage, which resulted from fatigue of the dry-film lubricant, is often called spalling [7.3-7.5].

Wear after initial sliding: Figure 7.14(a) shows the relatively smooth burnished surfaces in the upper and lower regions of the wear scar and the rougher surface at the center of the wear scar. Closer SEM examination and EDX analysis of the wear damage at the center of the wear scar showed that the flake-like wear debris (Fig. 7.14(b)) resulted from surface smearing and tearing of the dry-film lubricant. EDX analysis of the flake-like debris indicated that it mainly contained the elements of the $\mathrm{MoS}_{2}$ lubricant. Figure 7.14(c) shows a crater (dark area) where fragments of the dry-film lubricant were removed and the Ti-6Al-4V was exposed. EDX

NASA/TM-1999-107249, Chapter 7 

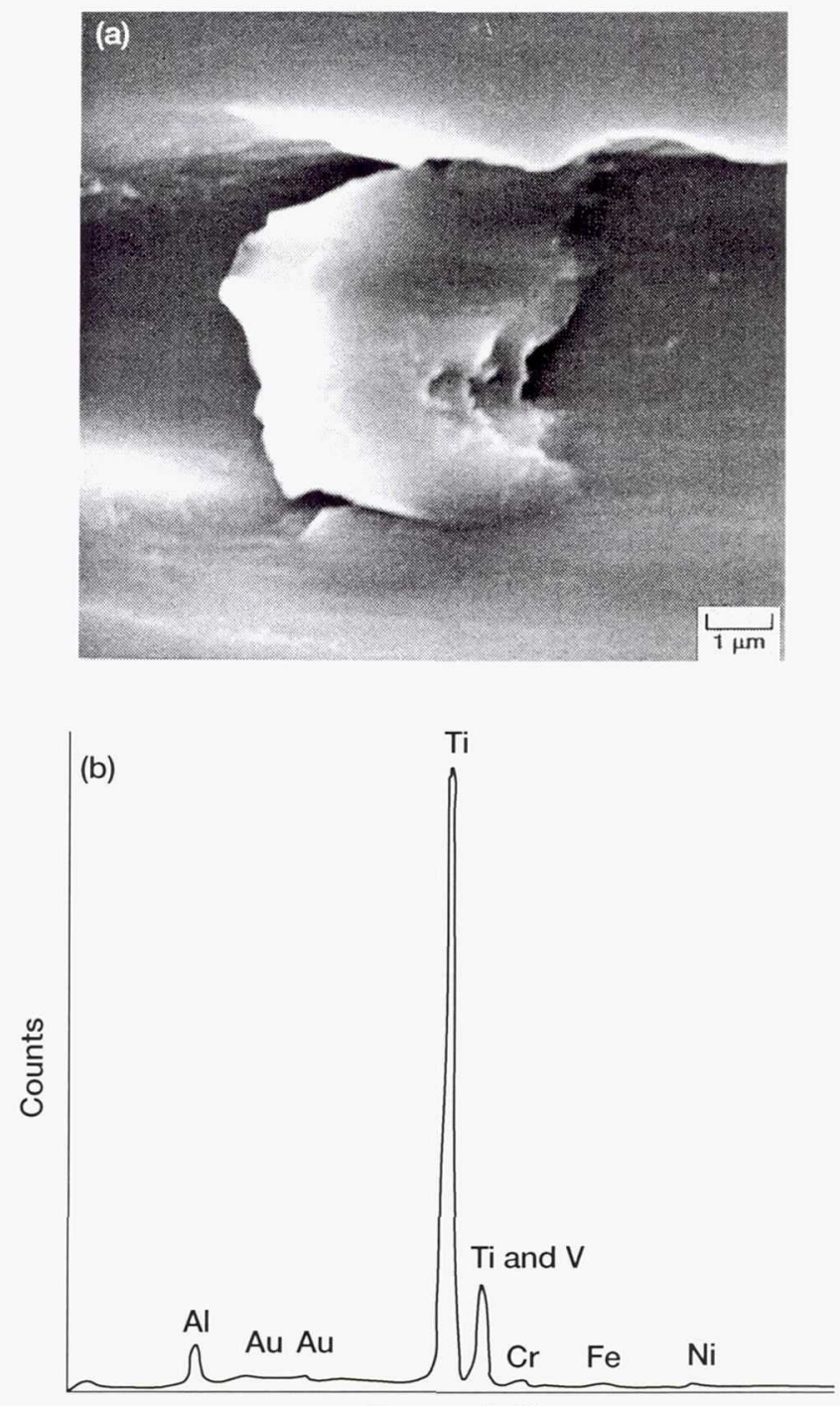

Energy, keV

Figure 7.11.-Clogged wear debris on wear scar on unlubricated Ti-6Al-4V pin after sliding against highnickel-content superalloy disk at $2.5 \mathrm{~N}$ in vacuum. (a) Secondary electron SEM image. (b) Spot EDX analysis. (Thin gold film used to reduce charging of mount is responsible for gold signal in spectrum.) 

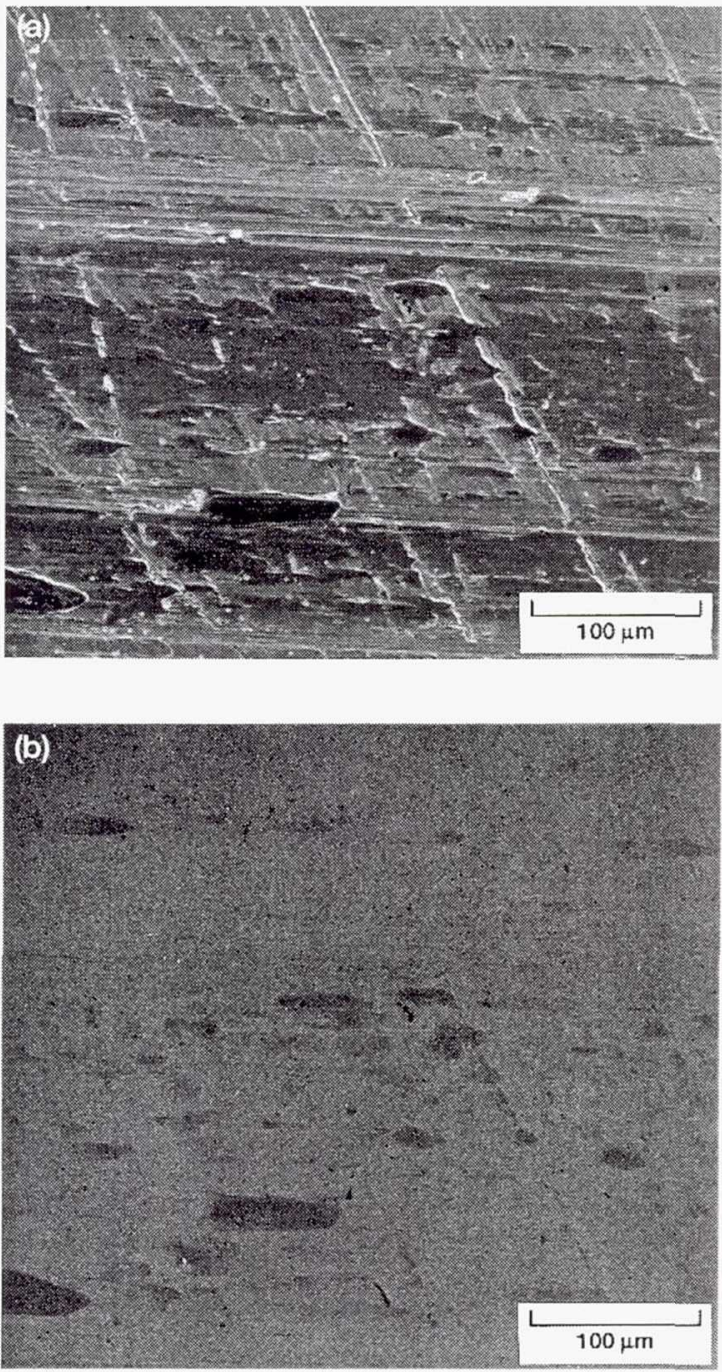

Figure 7.12.-Wear track on high-nickel-content superalloy disk after sliding by $\mathrm{Ti}-6 \mathrm{Al}-4 \mathrm{~V}$ pin at $2.5 \mathrm{~N}$ in vacuum, showing transfer patches of Ti-6Al-4V. (a) Secondary electron SEM image. (b) Backscatter electron SEM image. 

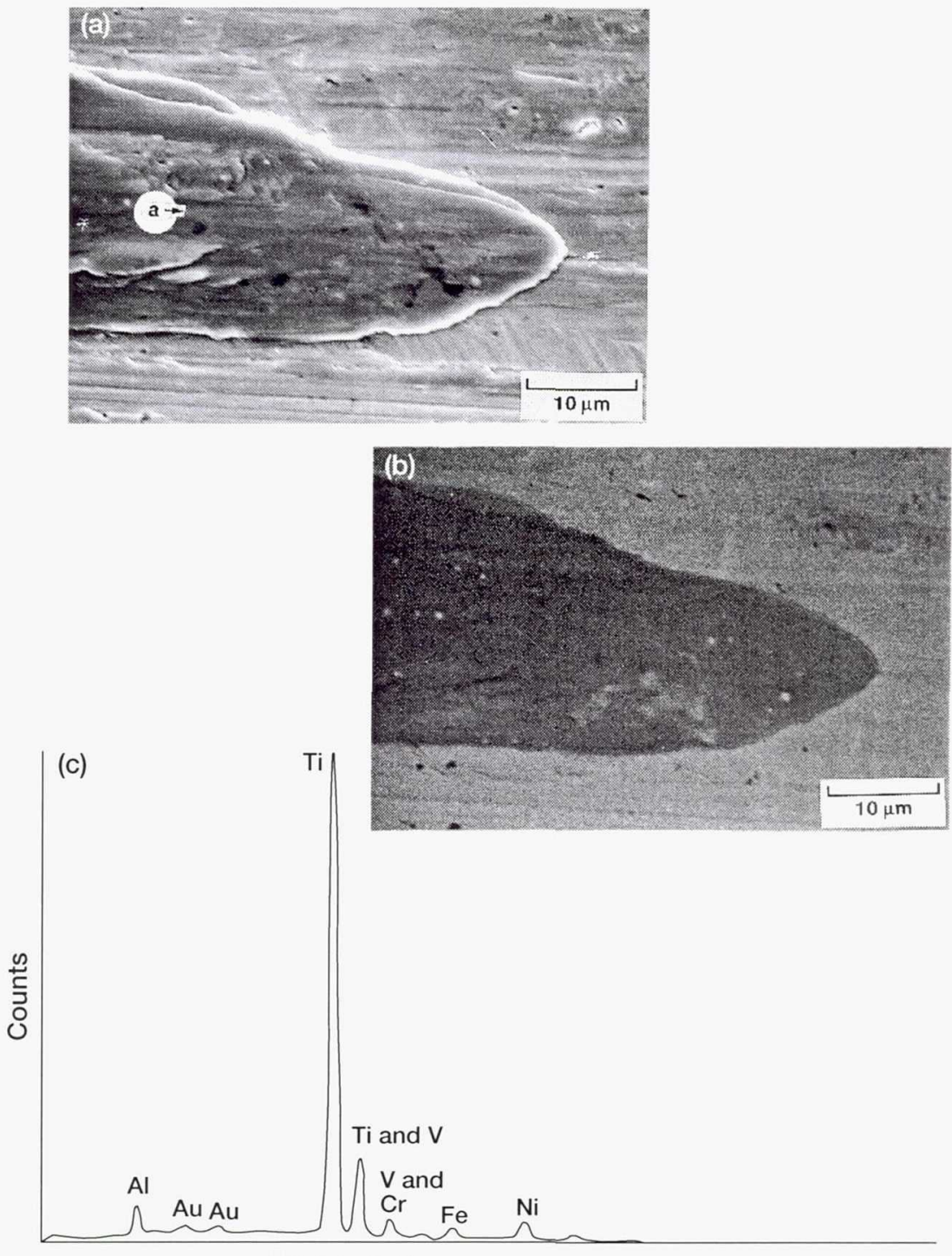

Energy, keV

Figure 7.13.- Large transferred patch of Ti- $6 \mathrm{Al}-4 \mathrm{~V}$ on high-nickel-content superalloy disk after sliding by Ti- $6 \mathrm{Al}-4 \mathrm{~V}$ pin at $2.5 \mathrm{~N}$ in vacuum, showing transfer patches of Ti-6AI-4V. (a) Secondary electron SEM image. (b) Backscatter electron SEM image. (c) EDX spectrum of transferred film on disk. (Data taken at point indicated in part (a). Thin gold film used to reduce charging of mount is responsible for gold signal in spectrum.)

NASA/TM—1999-107249, Chapter 7 

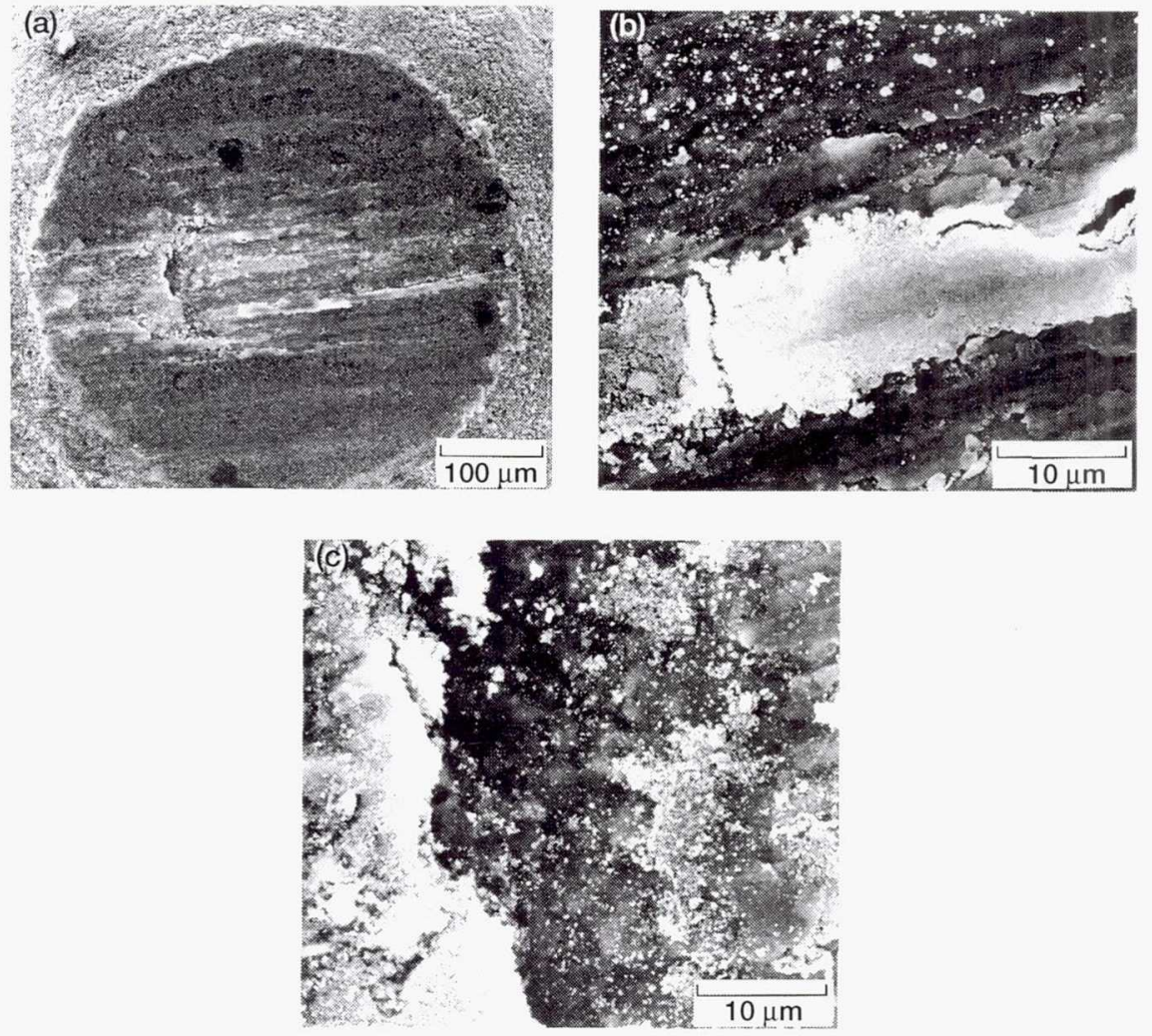

Figure 7.14.-Wear scar on dry-film-lubricated Ti-6Al-4V pin after sliding against high-nickel-content superalloy disk in vacuum. (a) Low-magnification overview showing relatively smooth surfaces at upper and lower areas with spalling and tearing at center. (b) Surface smearing and tearing at center resulting in particles separating from surface in form of flakes. (c) Spalling at center. 

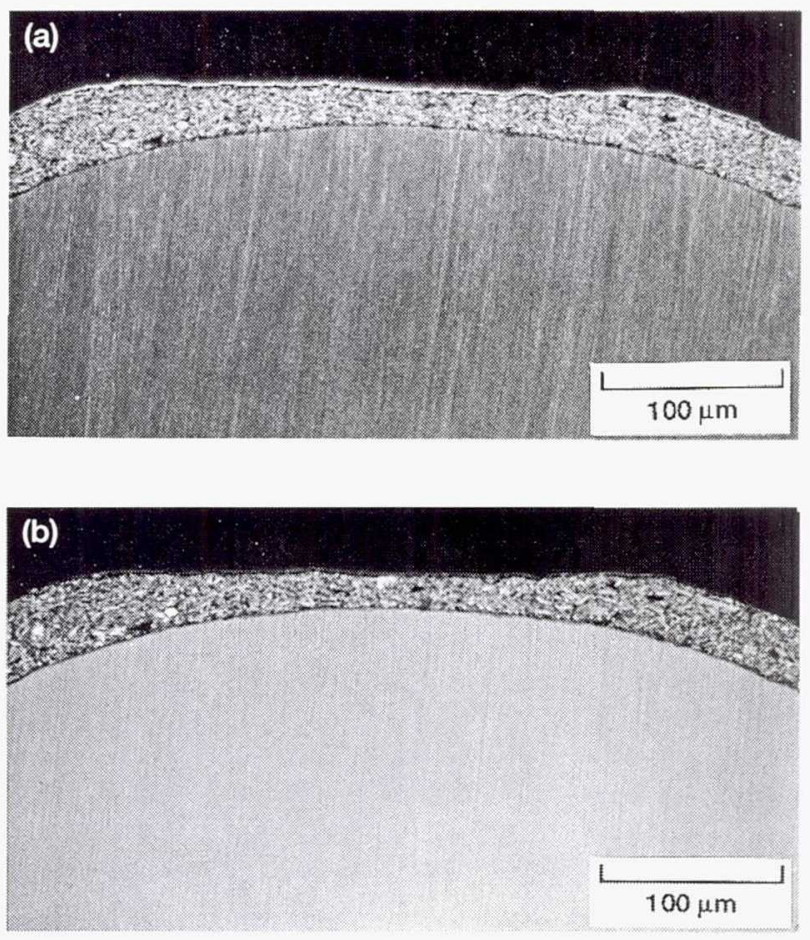

Figure 7.15.-Tapered cross section of worn surface of dry-film-lubricated Ti-6Al-4V pin at $45^{\circ}$ angle to worn surface. (a) Secondary electron SEM image. (b) Backscatter electron SEM image.

analysis of the crater indicated that it mainly contained elements of the Ti-6Al-4V. Even with spalling the extent of removal and fragmentation of the dry-film lubricant was minimal. Nevertheless, the dry-film lubricant occupied most of the overall wear scar.

Figures 7.15 and 7.16 show a tapered cross section of the worn surface of the dryfilm-lubricated Ti-6Al-4V pin at an angle of $45^{\circ}$ to the worn surface. The crosssection SEM photomicrographs clearly indicate that most of the dry-film lubricant remained even after about 170000 passes in vacuum. The film thickness of the remaining lubricant was about $15 \mu \mathrm{m}$. Close SEM examination revealed dense, amorphous-like material in the area right underneath the worn surface (Fig. 7.16(a)).

Figure 7.17 (a) shows the relatively smooth track on the high-nickel-content superalloy disk with transfer patches of the dry-film lubricant observed (even in the low-magnification view) mainly at the center of the wear track. Closer SEM examination of the center and upper regions of the track showed the transferred wear particles to be in the form of flakes and powders (Figs. 17(b) and (c)).

NASA/TM-1999-107249, Chapter 7 

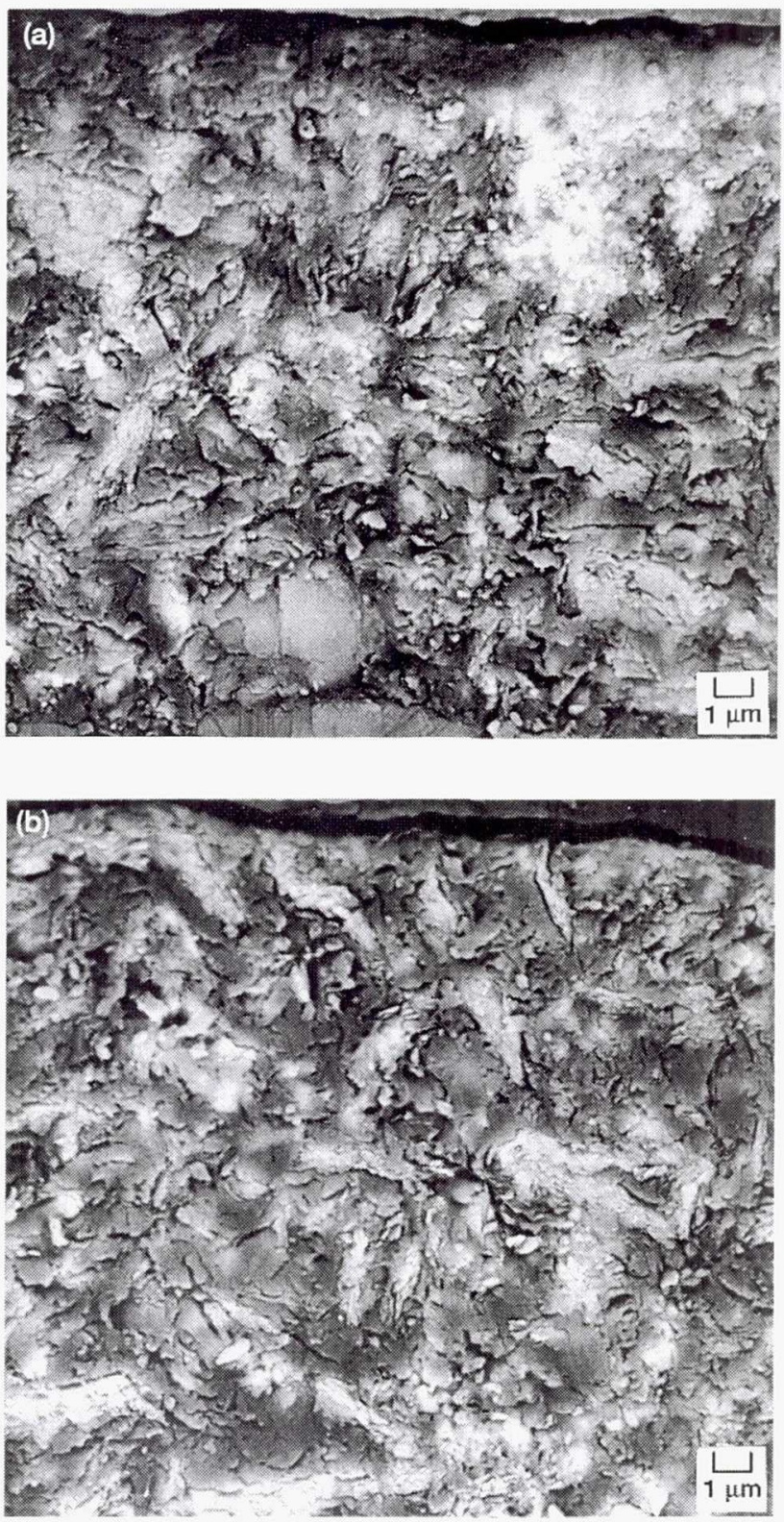

Figure 7.16.-Backscatter electron SEM image, showing comparison of microstructures. (a) Tapered cross section of worn surface. (b) Tapered cross section of as-coated area of dry-film lubricant. 

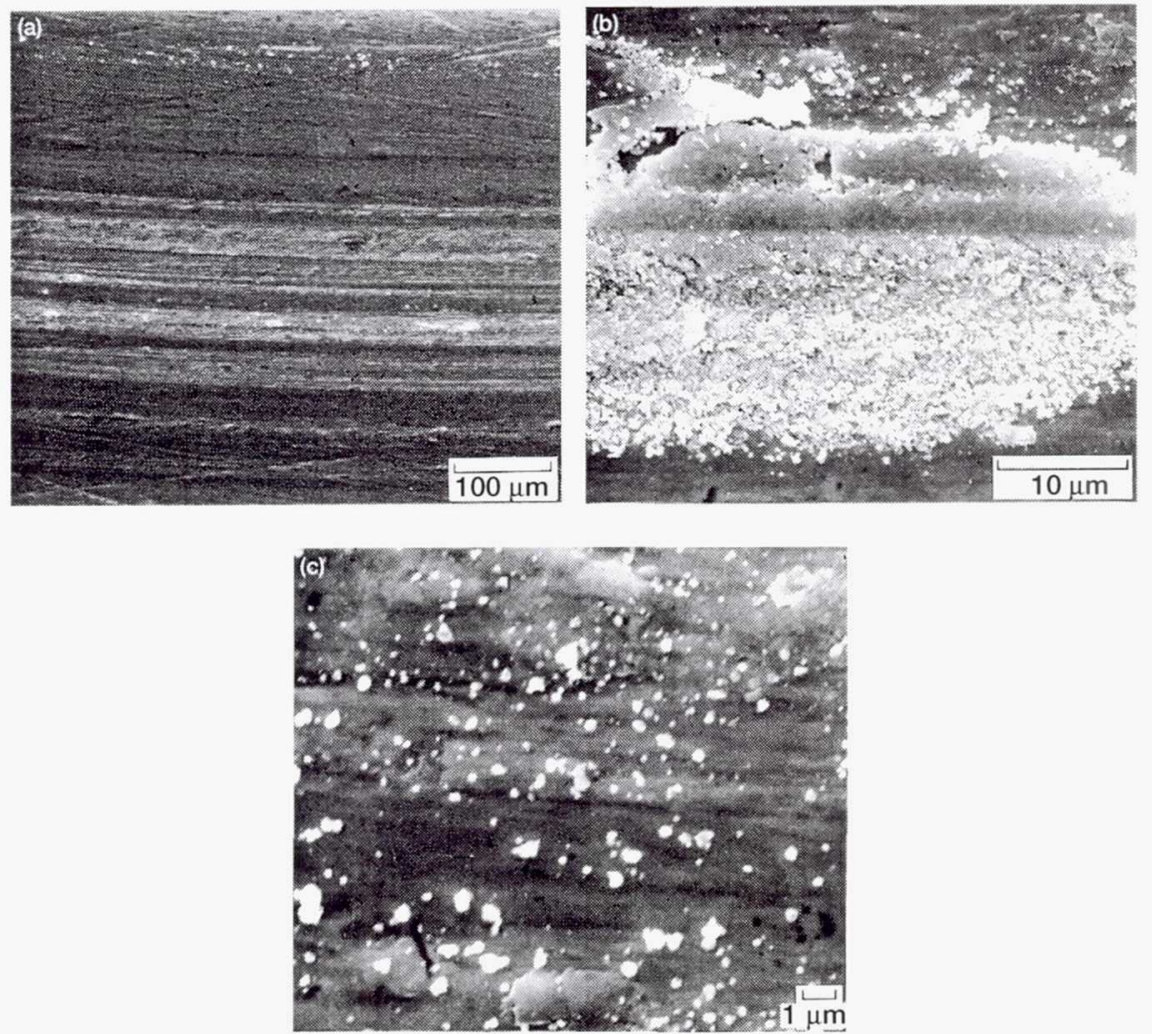

Figure 7.17.-Wear track on high-nickel-content superalloy disk after sliding by dry-film-lubricated Ti-6Al-4V pin in vacuum. (a) Low-magnification overview. (b) Detailed view showing transfer patches at center. (c) Detailed view showing powder-like wear debris of dry-film lubricant.

Wear after sliding in air and rerun in vacuum: Figures 7.18 to 7.24 show SEM photomicrographs of the worn surfaces of the dry-film-lubricated Ti-6Al-4V pin and the high-nickel-content superalloy disk run in air for 700 passes and then rerun in vacuum for 100 passes. Both plastic deformation and ductile fracture occurred in the dry-film-lubricated Ti-6Al-4V pin (Fig. 7.18(a)). The backscatter photomicrograph (Fig. 7.18(b)) reveals three different materials: (1) the light areas in the photomicrograph show where the transfer patches from the disk stayed on the Ti-6Al-4V pin, (2) the grayer areas show the Ti-6Al-4V substrate with no dry-film lubricant present, and (3) the salt-and-pepper-like areas around the edge of the wear scar show the dry-film lubricant. In addition to the major elements of the disk material, the transfer patches also contained elements such as molybdenum and 

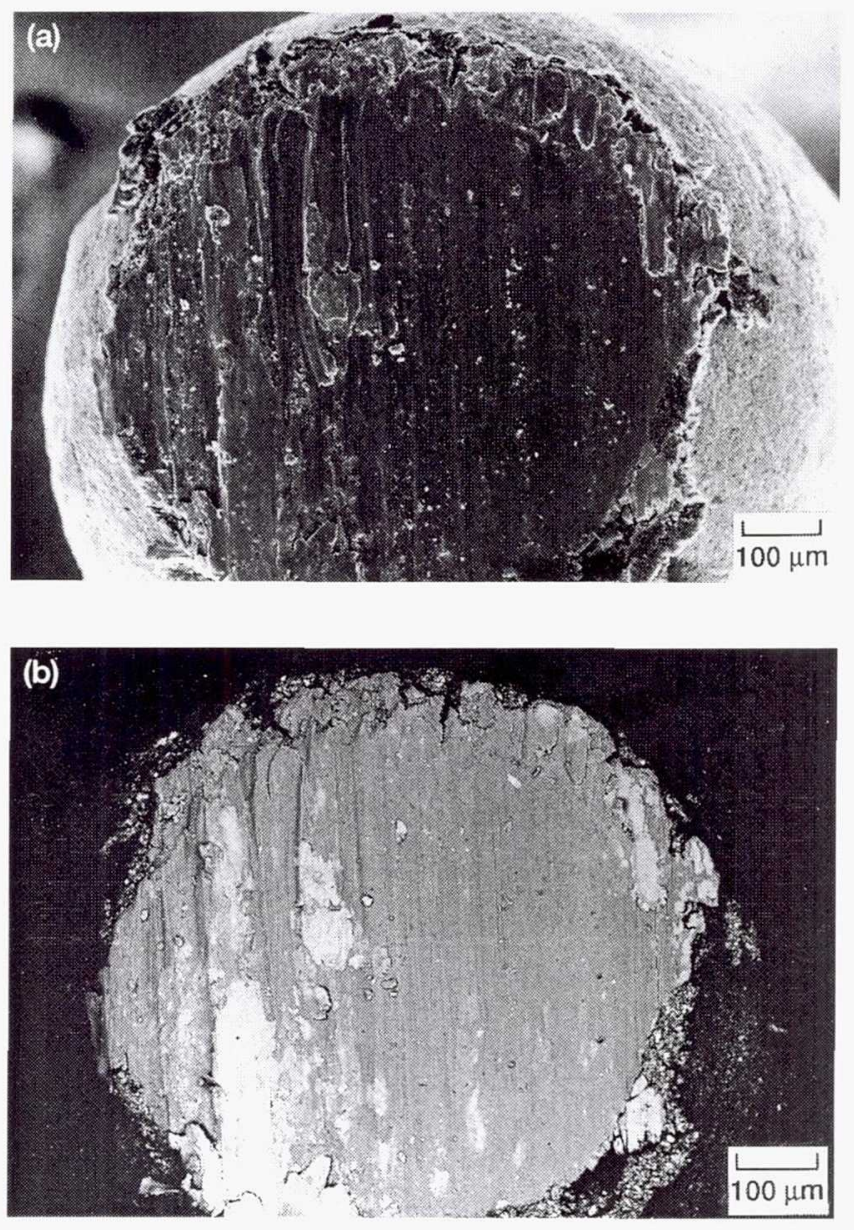

Figure 7.18.-Wear scar on dry-film-lubricated Ti-6AI-4V pin after sliding against high-nickel-content disk in humid air and then rerun in vacuum. (a) Secondary electron SEM image. (b) Backscatter electron SEM image. 


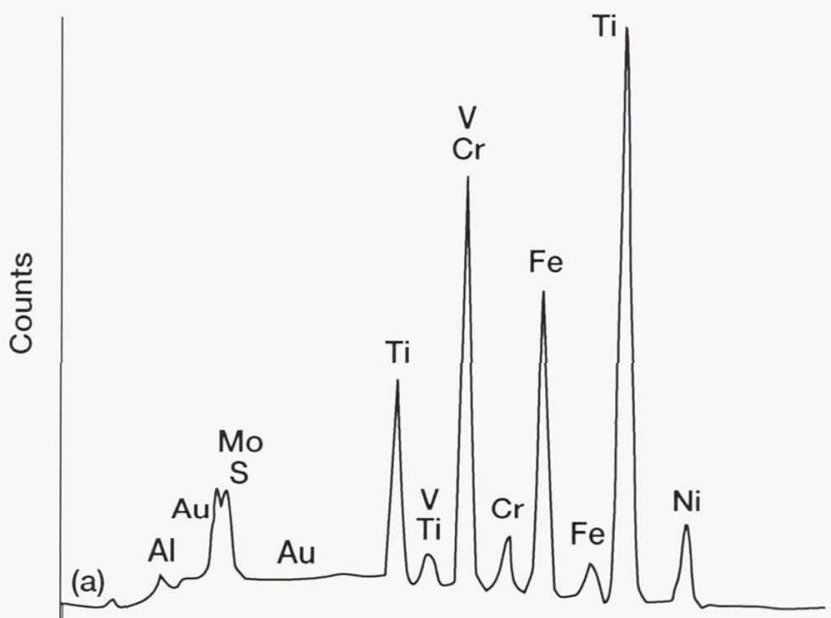

Energy, keV

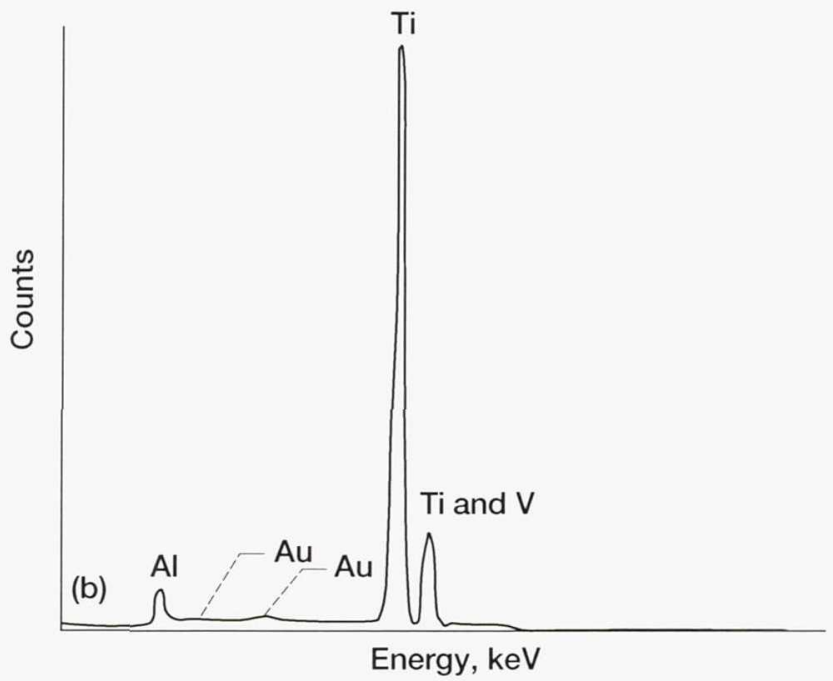

Figure 7.19.-EDX analysis of wear scar on dry-filmlubricated $\mathrm{Ti}-6 \mathrm{Al}-4 \mathrm{~V}$ pin after sliding against highnickel-content superalloy disk in humid air and then rerun in vacuum. (Thin gold film used to reduce charging of mount is responsible for gold signal in spectra.)

NASA/TM-1999-107249, Chapter 7 

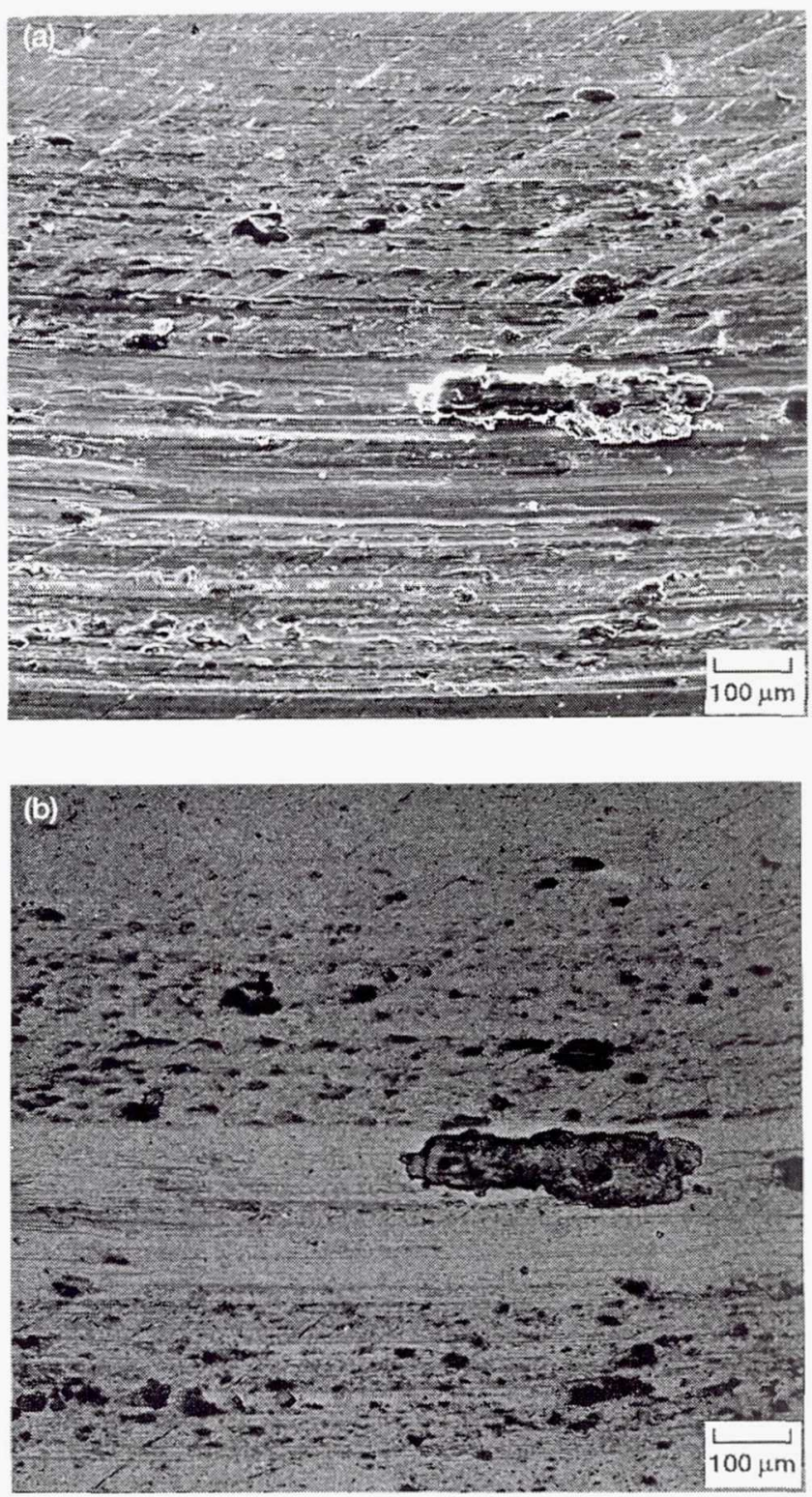

Figure 7.20.-Wear track on high-nickel-content superalloy disk after sliding by dry-film-lubricated Ti-6AI-4V pin in humid air and then rerun in vacuum. (a) Secondary electron SEM image. (b) Backscatter electron SEM image. 


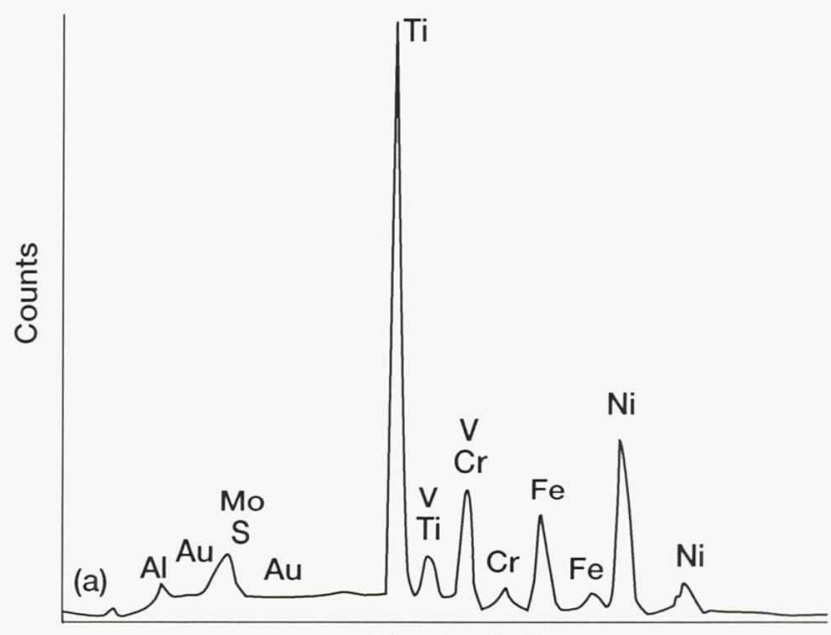

Energy, keV

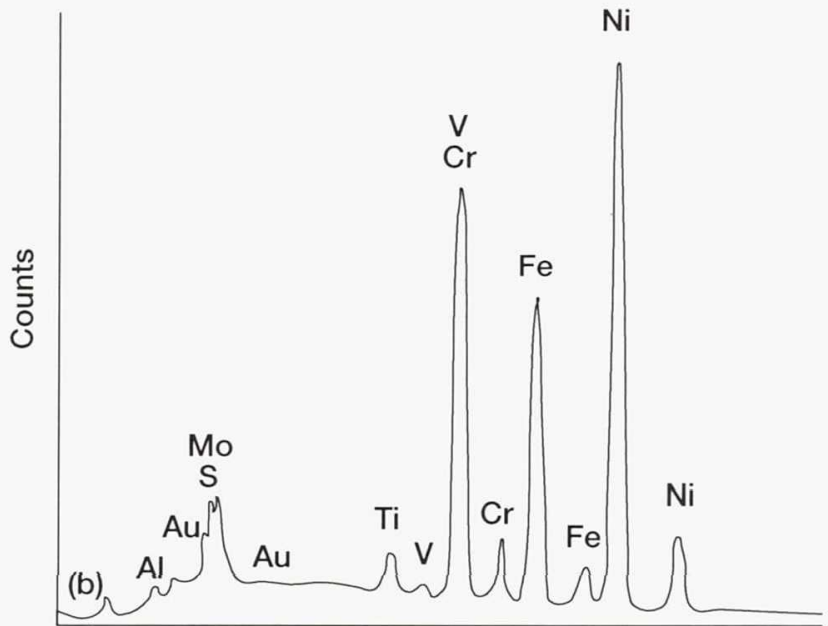

Energy, keV

Figure 7.21._EDX analysis of wear track on high-nickelcontent superalloy disk after sliding by dry-filmlubricated Ti-6Al-4V pin in humid air and then rerun in vacuum. (Thin gold film used to reduce charging of mount is responsible for gold signal in spectra.) 


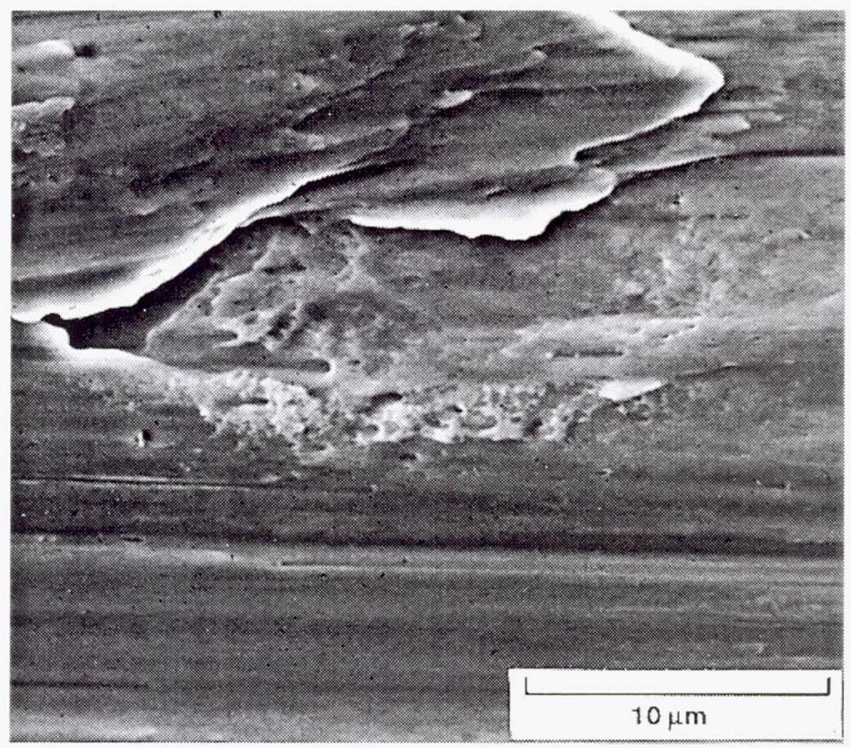

Figure 7.22.-SEM photomicrograph of wear track showing extensive plastic shearing in high-nickel-content superalloy disk after sliding by dry-film-lubricated Ti-6Al-4V pin in humid air and then rerun in vacuum.

sulfur from the lubricant (Fig. 7.19(a)). On the other hand, the gray areas contained only the elements of Ti-6Al-4V (Fig. 7.19(b)).

The large patches seen on the disk wear track in Fig. 7.20(a) are also apparent in the backscatter photomicrograph of Fig. 7.20(b), which indicated the dark areas to be transfer patches from the Ti-6Al-4V. Further, the EDX analysis (Fig. 7.21(a)) of a transfer patch shows that it mainly contained elements from the Ti-6Al-4V with a small amount of elements from the $\mathrm{MoS}_{2}$ dry-film lubricant. The rest of the areas in the wear track contained relatively smaller amounts of elements from the Ti-6Al$4 \mathrm{~V}$ and the dry-film lubricant (Fig. 7.21(b)). Closer SEM examination (Fig. 7.22) of the wear track revealed extensive plastic shearing of the high-nickelcontent superalloy disk.

Figure 7.23, a tapered cross section of the worn surface of the dry-film-lubricated Ti-6Al-4V pin, shows clearly that the dry-film lubricant was not present on the worn surface. Further, in the overview photomicrograph, extrusion out of the wear scar and transfer patches of the disk material are also well defined because of effective atomic number contrast. Plastic deformation of the Ti-6Al-4V (extrusion out of the wear scar) and local solid-phase welding (cold welding) between the Ti-6Al-4V and transfer patches of the disk material (often called scuffing or scoring) were well defined by the backscatter electron SEM images (Fig. 7.24).

NASA/TM-1999-107249, Chapter 7 


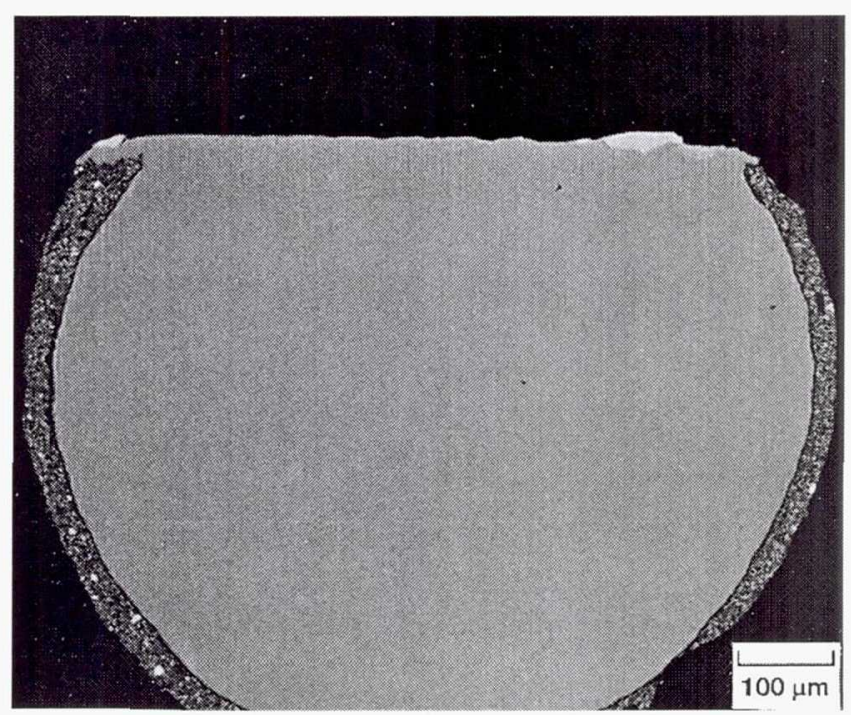

Figure 7.23.-Overview (backscatter electron SEM image) of tapered cross section at $45^{\circ}$ angle to worn surface of dry-film-lubricated Ti-6Al-4V pin after sliding against high-nickel-content superalloy disk in humid air and then rerun in vacuum, showing extrusion out of wear scar, transfer patches of high-nickel-content superalloy, and no dry-film lubricant on worn surface.

Thus, the worn surfaces of the pin and disk first run in humid air and then rerun in vacuum were completely different from the worn surfaces of the pin and disk run only in vacuum. The surfaces worn in humid air (Figs. 7.18 and 7.20) exhibited galling accompanied by severe surface damage and extensive transfer of the Ti-6Al$4 \mathrm{~V}$ to the high-nickel-content superalloy disk, or vice versa.

\subsubsection{Summary of Results and Conclusions for Case Study A}

In the investigation of the Galileo antenna anomaly the following results were obtained:

1. The performance of the dry-film lubricant in air was poor when compared with its performance in vacuum. The coefficient of friction for the dry-filmlubricated system in vacuum was about 0.04 ; the value in air was 0.13 . The endurance life of the dry-film lubricant was about three orders of magnitude longer in vacuum than in air

2. The worn surfaces of the dry-film-lubricated Ti-6Al-4V pin and the highnickel-content superalloy disk first run in humid air and then rerun in vacuum 

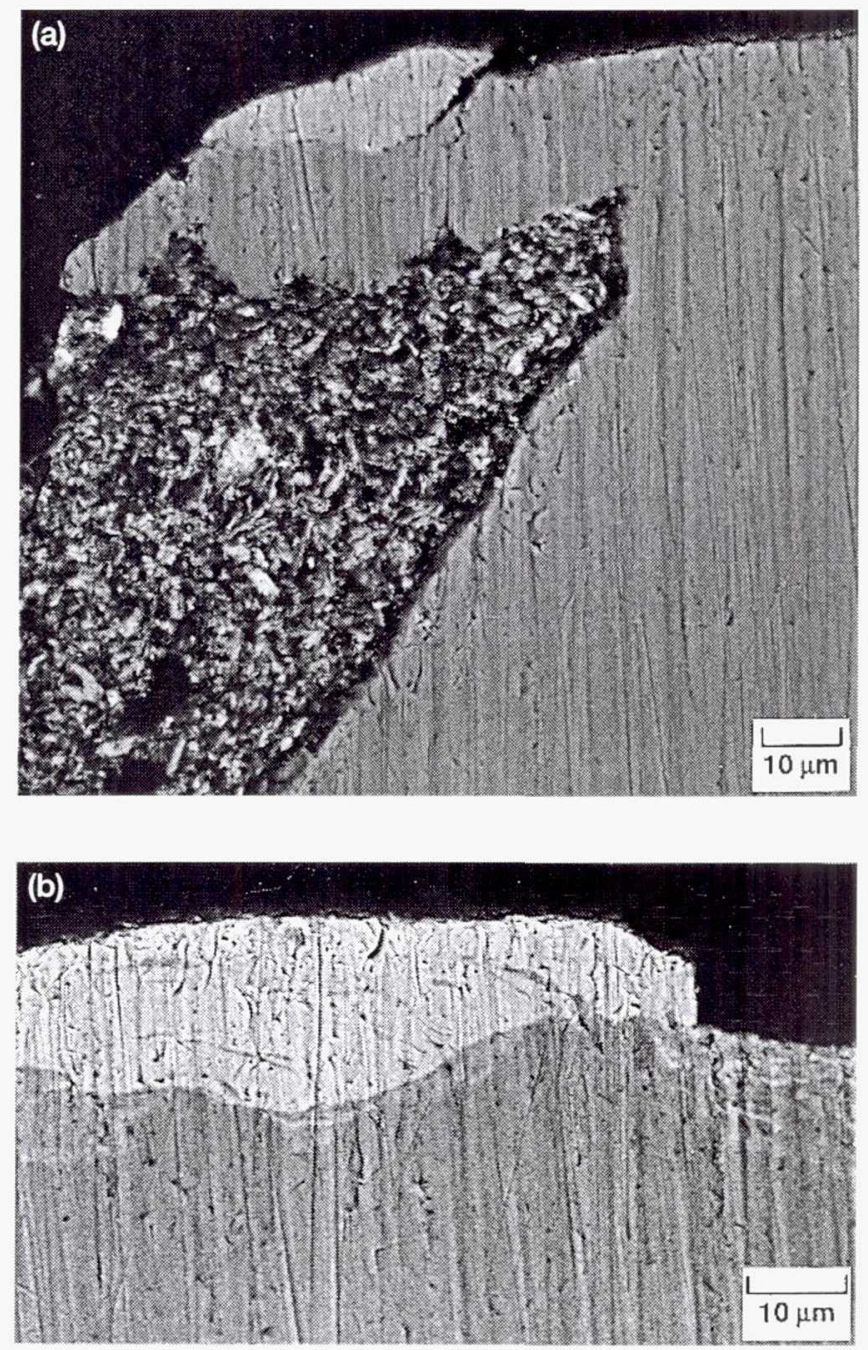

Figure 7.24.-Backscatter electron SEM images of tapered cross section of worn surface of dry-film-lubricated Ti-6Al-4V pin after sliding against high-nickel-content superalloy disk in humid air and then rerun in vacuum. (a) Showing extrusion out of wear scar. (b) Showing transfer patch of high-nickel-content superalloy on worn surface of dry-film-lubricated Ti-6Al-4V pin. 
were completely different from the surfaces of the pin and disk run only in vacuum. Galling occurred in the former conditions, whereas spalling occurred in the latter conditions.

3. When galling occurred in the contact between the dry-film-lubricated Ti-6Al$4 \mathrm{~V}$ pin and the high-nickel-content superalloy disk first run in humid air and then rerun in vacuum, the coefficient of friction rose to about 0.32 in humid air and to 1.4 in vacuum. The galling was accompanied by severe surface damage and extensive transfer of the Ti-6Al-4V to the high-nickel-content superalloy, or vice versa.

4. When spalling occurred in the dry-film-lubricated Ti-6Al-4V pin run against the high-nickel-content superalloy disk only in vacuum, the coefficient of friction rose to 0.36 or greater. The wear damage, however, self-healed when sliding was stopped and then rerun in vacuum, and the coefficient of friction decreased to 0.05 .

The aforementioned tribological results were also constructively reviewed in Johnson's paper [7.5]. He concluded, "The high contact stress on the V-groove pin/ socket interfaces destroyed the integrity of the lubricant film and started the chain of events that led to the deployment anomaly....The use of dry lubricant, specifically molybdenum disulfide, on a mechanism that is going to be operated in an atmosphere should be carefully evaluated. The wear rate of the $\mathrm{MoS}_{2}$ in air is so much higher than in a vacuum that any coatings could be worn out by in-air testing and not provide the desired lubrication when needed. The pins and sockets on the highgain antenna that received the greatest amount of relative motion due to the shipping method were the same ones that were exercised most by the vibration testing. These are also the same pins and sockets that are stuck on the spacecraft. One solution to the problem of ambient testing wearing out the lubricant coating would be to replace the lubricated components just prior to launch so there is a virgin lubricant surface for the flight operation."

As Peter Jost [7.2] stated, in the operation of space mechanisms functional reliability is, of course, vital. Even a small tribological failure can clearly lead to catastrophic results. The absence of the required knowledge of tribology can act as a severe brake on the development of new technologies. Tribological reliability of mechanical systems in the highest order will be secured in the operation of many interacting surfaces in relative motion if greater attention (such as the following examples) will be paid to tribology:

1. The effects of adhesion or cold welding on mechanical problems in deep space vehicles must be investigated.

2. Simulation experiments must be conducted on various adhesion couples in different environments and temperature ranges.

3. Particular variables contributing to the mechanism of the adhesion process must be scientifically examined.

NASA/TM-1999-107249, Chapter 7 


\subsection{Case Study B: Space Shuttle Orbiter's Quad Check Valve Failures}

\subsubsection{Quad Check Valve Failures}

The space shuttle orbital maneuvering system (OMS) provides the thrust for orbit insertion, circularization, orbit transfer, rendezvous, and deorbit. The space shuttle reaction control system (RCS) provides the thrust for pitch, yaw, and roll maneuvers and for small velocity changes along the orbiter axis. The OMS/RCS left- and righthand pods are attached to the upper aft fuselage on the left and right sides (Fig. 7.25). Each pod is divided into two compartments: the OMS housing and the RCS housing. RCS thrusters and associated propellant feed lines are also attached to the forward module.

The space shuttle quad check valve (QCV) is used on both the orbiter's OMS and RCS. The function of the QCV is to allow helium pressurant to flow downstream while precluding upstream backflow of helium and propellant vapors or liquids (Fig. 7.26). Each unit consists of four check valve module elements arranged as two parallel assemblies with two series check valve modules. A significant number of QCV failures (poppet stuck open) have resulted in the removal of QCV's from the orbiter.

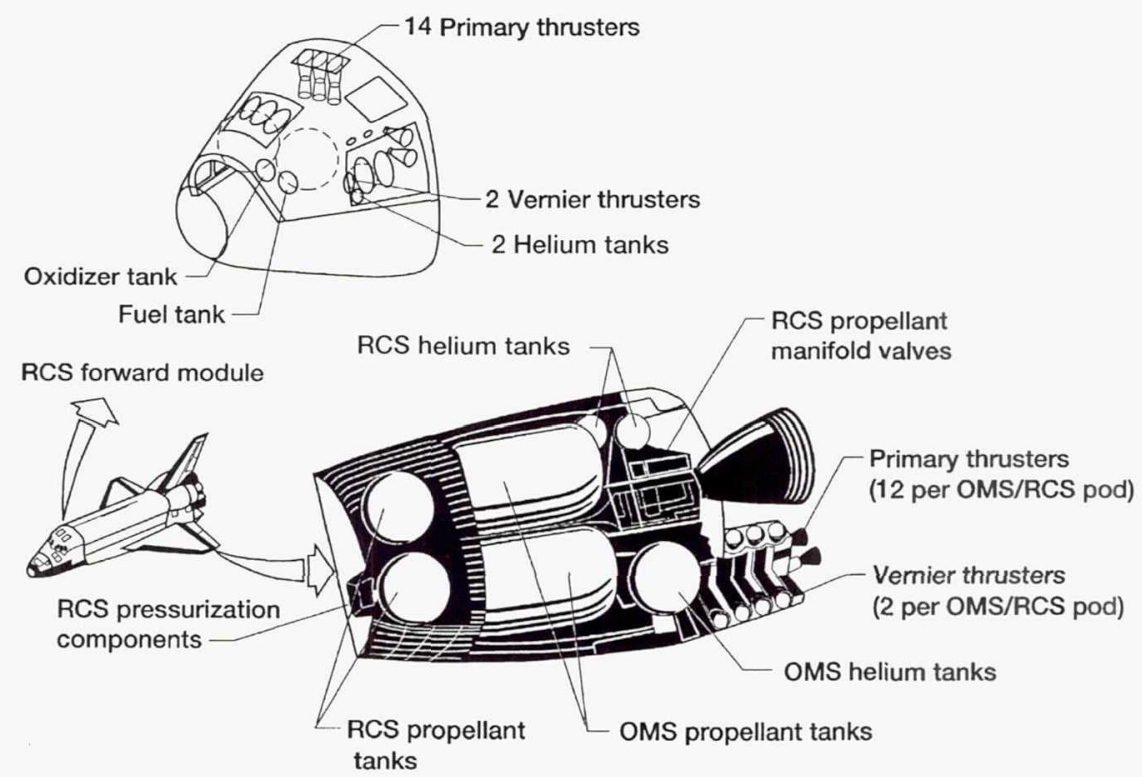

Figure 7.25.-Space shuttle orbiter's control systems.

NASA/TM-1999-107249, Chapter 7 


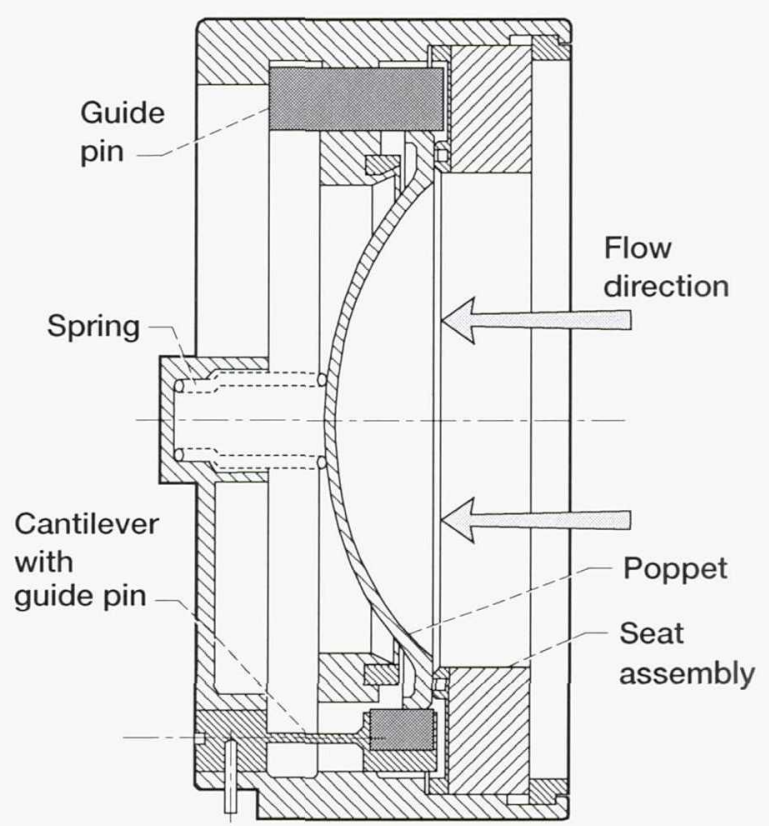

Figure 7.26.-Quad check valve design.

\subsubsection{Failure Investigation}

Because of leakage and cracking pressure problems more than two dozen QCV's have been removed for repair and overhaul. Evidence not always present includes sapphire pin wear, propellant residues, and small cracks in the valve seat, which is coated with chemical-vapor-deposited tungsten and tungsten carbide (W/WC). Issues are as follows:

1. Sticking and seizing up of the W/WC poppet on the sapphire guide pin

2. Poor wear couple between the W/WC poppet and the sapphire guide pin

3. Spring force, originally designed to meet requirements for low cracking pressure, lower than necessary to close poppet

\subsubsection{Investigation of Friction, Wear, and Lubrication}

\subsubsection{Experimental Conditions}

Because QCV's in-orbit are not exposed to the space vacuum environment, reciprocating sliding friction experiments were conducted in the atmosphere. The

NASA/TM-1999-107249, Chapter 7 
TABLE 7.2.-EXPERIMENTS FOR CASE STUDY B

(a) Conditions of friction and wear experiments

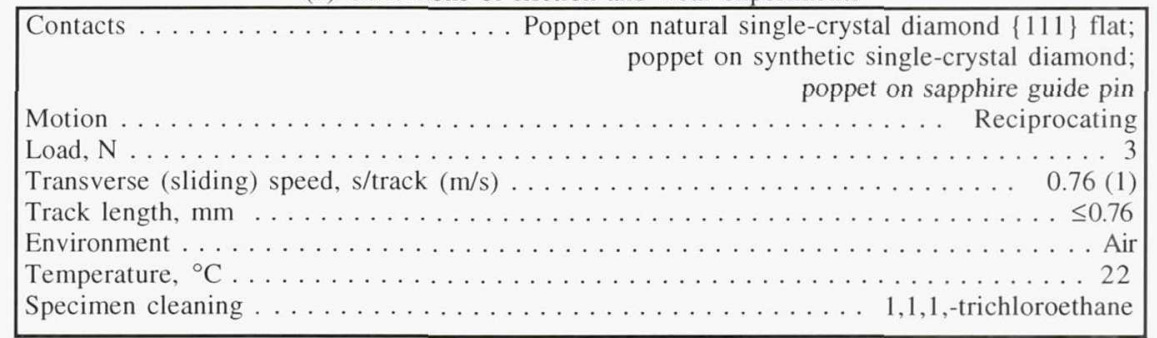

(b) Contact configurations

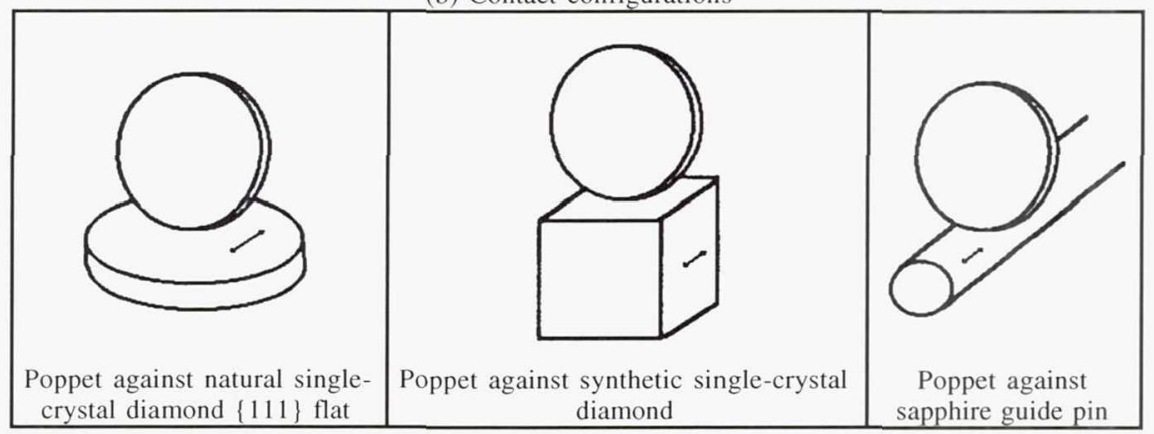

(c) Specimen sizes

Poppet .............. Approximately $30 \mathrm{~mm}$ in diameter with rounded circular edge

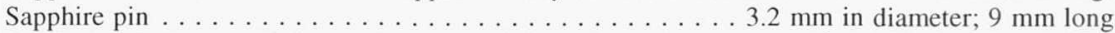

Synthetic single-crystal diamond . . . . 1.4-mm by $1.4-\mathrm{mm}$ rectangular surface; $1.1 \mathrm{~mm}$ thick Natural single-crystal $\{111\}$ diamond .......... $30-\mathrm{mm}^{2}$ flat platelet; $2 \mathrm{~mm}$ thick

conditions and contact configurations (Table 7.2) were chosen to simulate as closely as possible the conditions that the poppet-pin interface of a QCV may have experienced. The poppet traveled back and forth, retracing its tracks on the bare surfaces of the counterpart materials: sapphire, synthetic single-crystal diamond, and natural single-crystal $\{111\}$ diamond.

The poppet is made of a tungsten material with dispersed tungsten carbides (W/16 wt\% WC) produced by a chemical vapor deposition (CVD) process (i.e., deposited on a commercially pure molybdenum mandrel). Further, two types of poppet were tested: one with a polytetrafluoroethylene (PTFE) top layer coated on the W/WC poppet and one without the PTFE top layer (i.e., a bare W/WC poppet). Figure 7.27 presents Vickers microhardnesses for the PTFE-coated poppet and the bare poppet as a function of indentation load. Note that the seat also uses the W/WC chemical vapor deposited on a thoriated tungsten mandrel.

NASA/TM-1999-107249, Chapter 7 

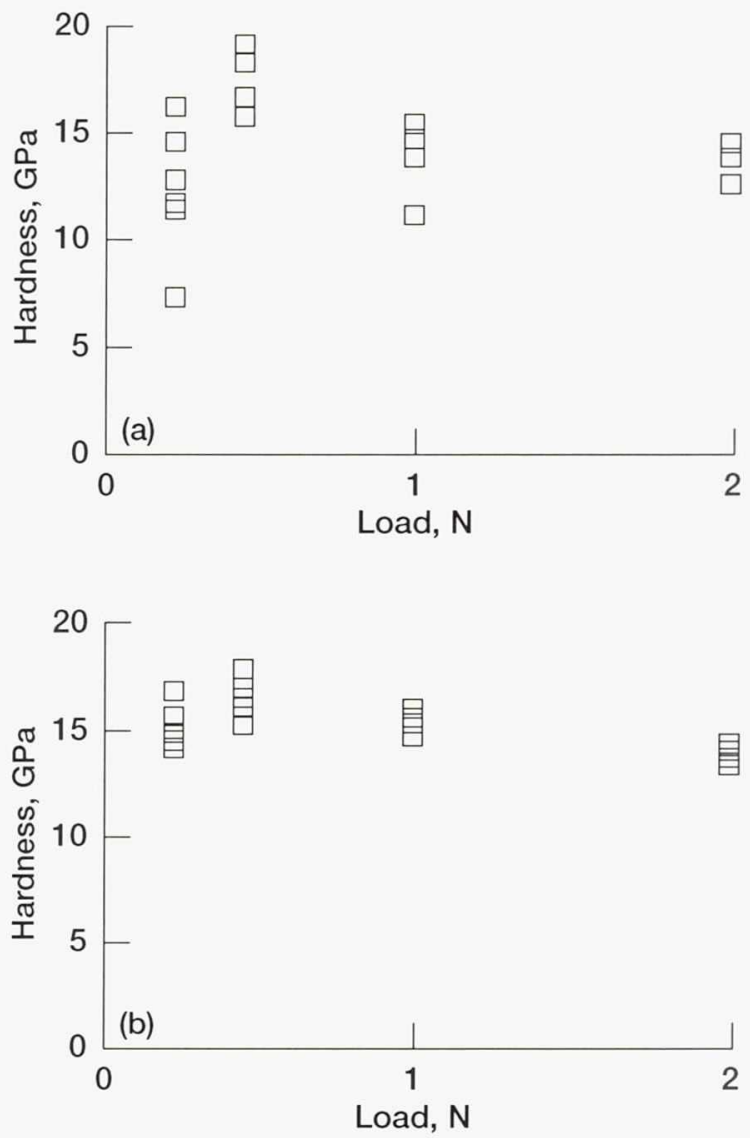

Figure 7.27.-Vickers microhardnesses of (a) PTFEcoated W/WC poppet and (b) bare W/WC poppet as function of indentation load.

\subsubsection{Sliding Friction in Air}

PTFE-coated W/WC poppet.-Figure 7.28 shows the mean coefficients of friction for the PTFE-coated W/WC poppet in contact with bare sapphire, synthetic single-crystal diamond, and natural single-crystal $\{111\}$ diamond in air. The steady-state coefficients of friction in contact with the natural and synthetic diamond were 0.06 and 0.03 , respectively, and the friction was smooth with no stick-slip behavior. On the other hand, the poppet in contact with the bare sapphire had a high steady-state coefficient of friction (approximately 0.25 , or greater than that of the diamonds by a factor of approximately 4 to 8 ). Also, the friction trace for

NASA/TM-1999-107249, Chapter 7 


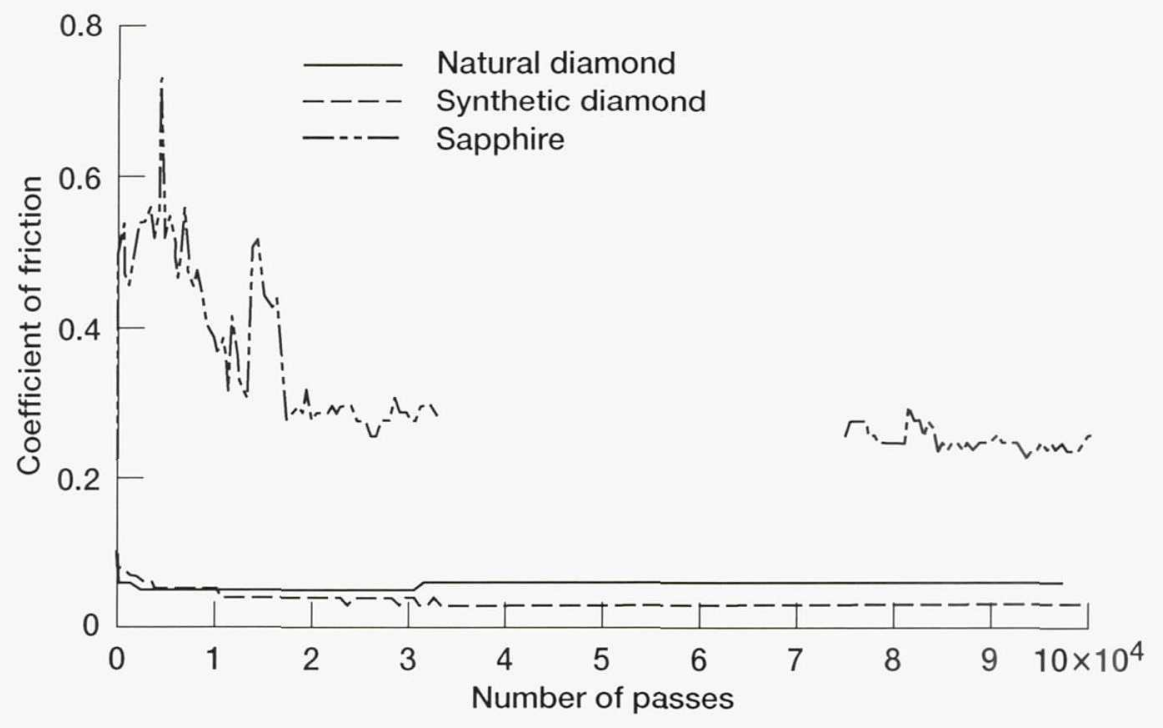

Figure 7.28.-Coefficients of friction for PTFE-coated W/WC poppet sliding against sapphire, synthetic diamond, and natural diamond as function of number of passes in air.

the sapphire indicated that the friction was erratic and unstable with stick-slip behavior. In the conditions examined with the sapphire pin PTFE was not an effective lubricating film.

Bare W/WC poppet.-Figure 7.29 shows the mean coefficients of friction for the bare W/WC poppet in contact with bare sapphire, synthetic single-crystal diamond, and natural single-crystal $\{111\}$ diamond in air. The steady-state coefficient of friction in contact with the natural and synthetic diamond was 0.02 , and the friction was smooth and calm with no stick-slip behavior. On the other hand, the bare poppet in contact with bare sapphire had a high steady-state coefficient of friction (approximately 0.7 , or greater than that of the diamonds by a factor of approximately 35). Also, the friction trace for the sapphire indicated that the friction was erratic and unstable, with stick-slip behavior between 300 and 1600 passes. With the diamonds the steady-state coefficients of friction were lower when sliding against the bare poppet than when sliding against the PTFE-coated poppet.

\subsubsection{Wear Damage}

PTFE-coated poppet.-Figure 7.30 presents SEM photomicrographs of the wear track on the sapphire and of the wear scar on the PTFE-coated W/WC poppet after 100000 passes in air. The sapphire wear track contained transferred materials and wear debris. Closer SEM examination at high magnification clearly showed

NASA/TM-1999-107249, Chapter 7 

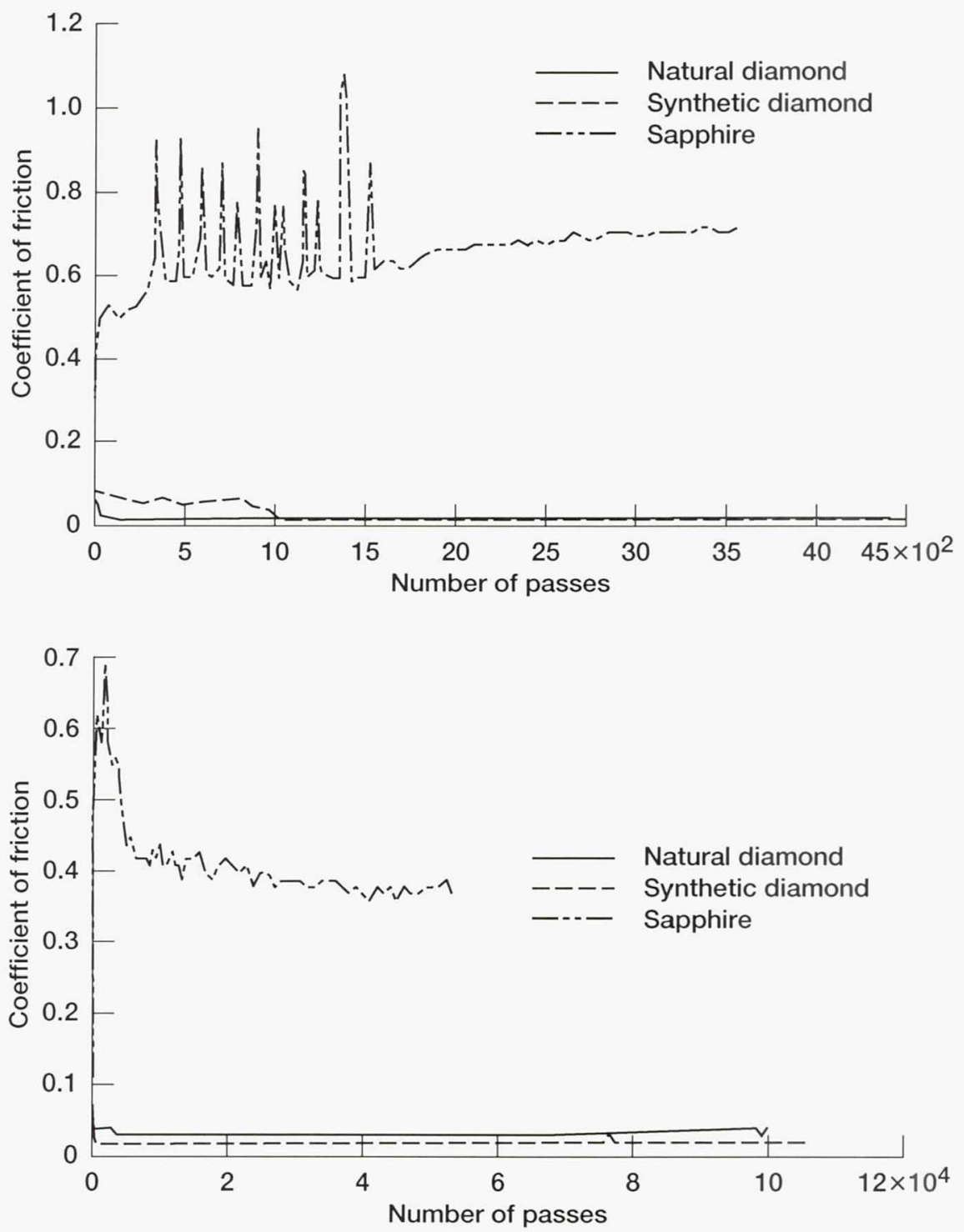

Figure 7.29.-Coefficients of friction for bare W/WC poppet sliding against sapphire, synthetic diamond, and natural diamond as function of number of passes in air.

NASA/TM—1999-107249, Chapter 7 

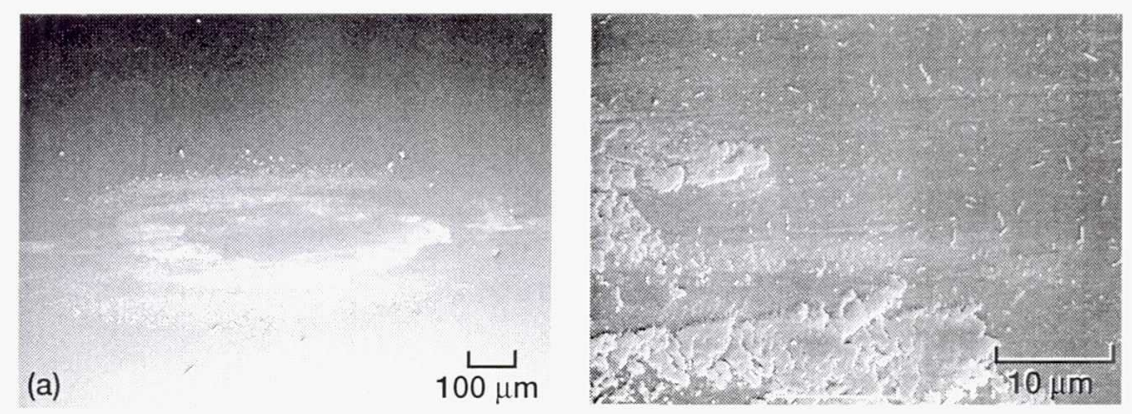

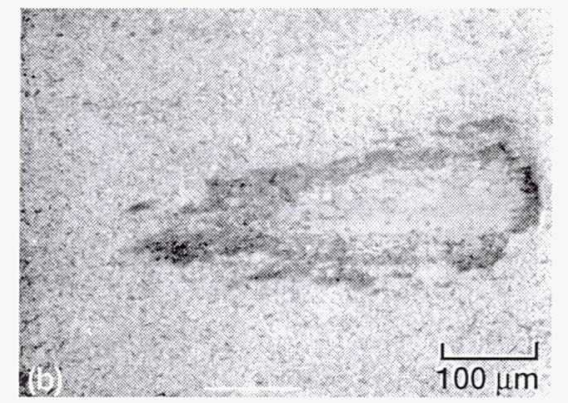

Overview

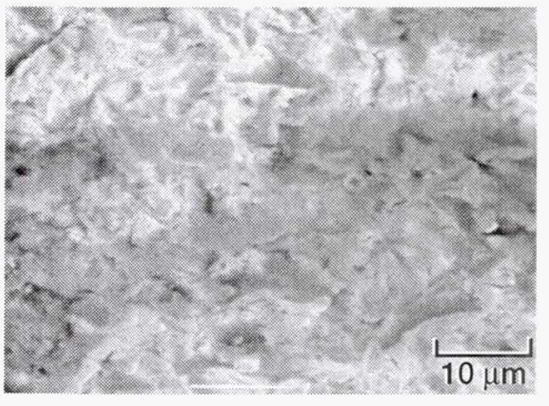

High magnification

Figure 7.30.-SEM photomicrographs of (a) wear track on sapphire and (b) wear scar on PTFE-coated W/WC poppet.

transfer patches of materials from the poppet. An EDX spectrum taken at the center of the sapphire wear track (Fig. 7.31(a)) indicated the presence of tungsten from the counterpart material. On the other hand, the wear scar produced on the PTFE-coated W/WC poppet had almost no transferred material from the sapphire (Figs. 7.30(b) and $7.31(\mathrm{~b}))$.

The as-received surface of synthetic diamond is a cleavage face of a single crystal. This surface is flat and smooth but contains cleavage steps. The steps between smoothly cleaved planes with slightly different height levels generally have sharp edges (Fig. 7.32). Figure 7.33 presents SEM photomicrographs of the wear track on synthetic single-crystal diamond and of the wear scar on the PTFEcoated W/WC poppet after 100000 passes in air. Because the sliding direction was almost perpendicular to the cleavage steps on the diamond surface in this case, the sharp edges of the cleavage steps cut and plowed the surface of the PTFE-coated W/WC poppet. Therefore, the diamond wear track contained wear debris produced by this cutting and plowing action. Closer SEM examination at high magnification clearly showed wear debris particles and patches of materials from the poppet. An EDX spectrum taken at the patches on the diamond wear track (Fig. 7.34) indicated the presence of tungsten from the poppet materials. On the other hand, the wear scar 

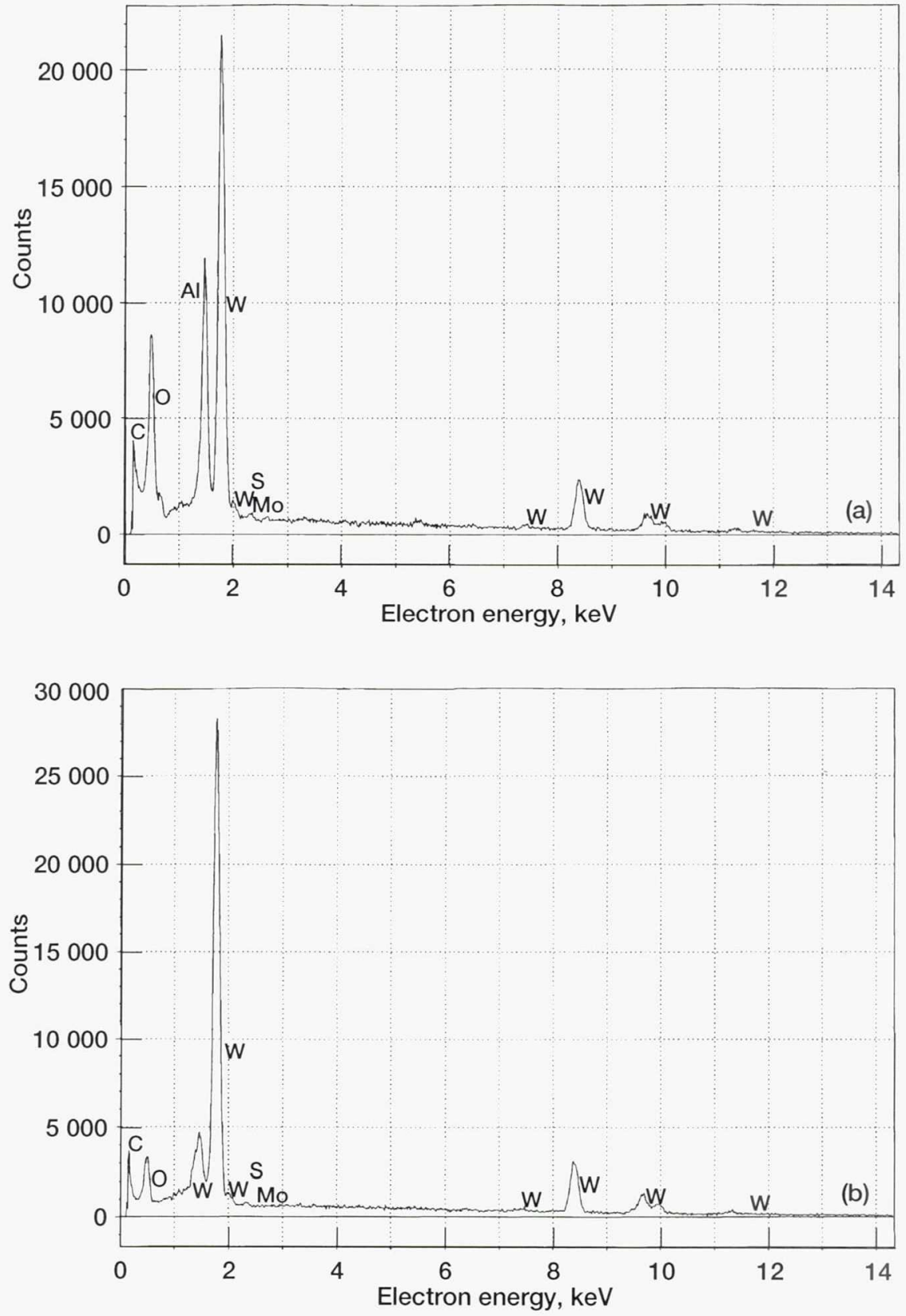

Figure 7.31.-EDX spectra of (a) wear track on sapphire and (b) wear scar on PTFE-coated W/WC poppet.

NASA/TM-1999-107249, Chapter 7 


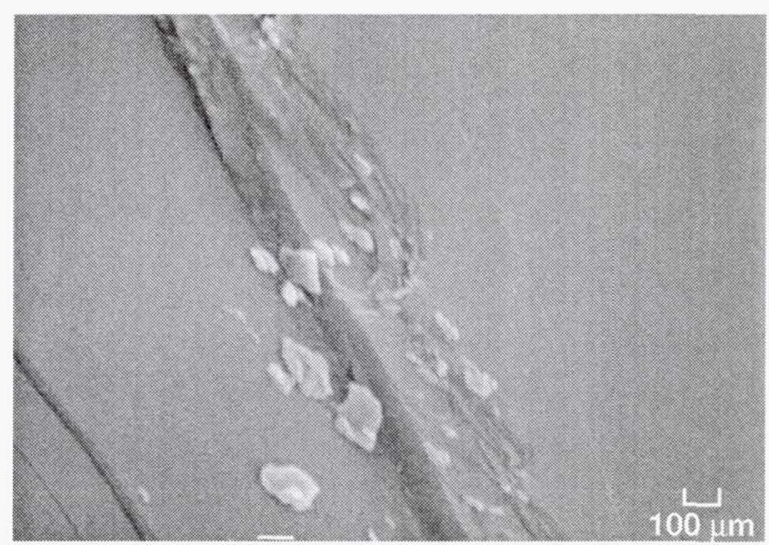

Figure 7.32.-Cleavage steps on synthetic singlecrystal diamond surface.
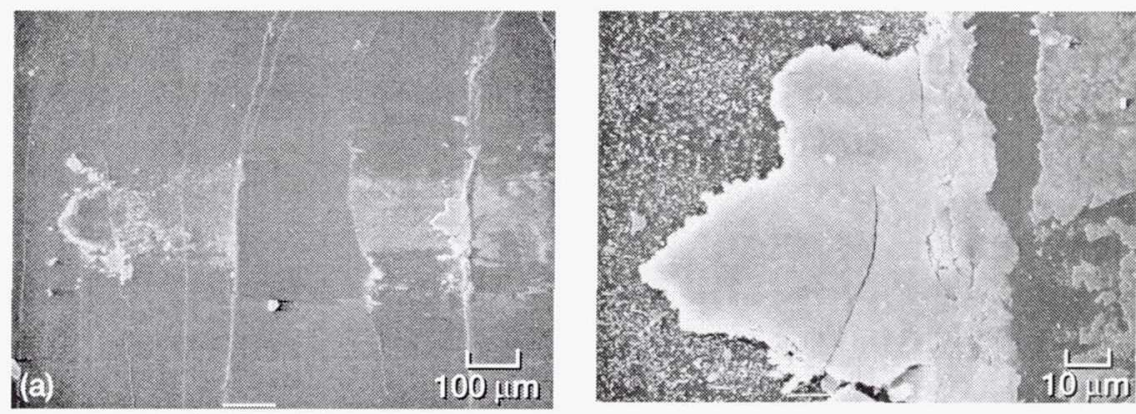

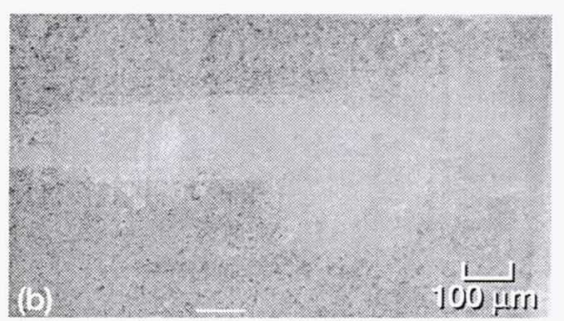

Overview

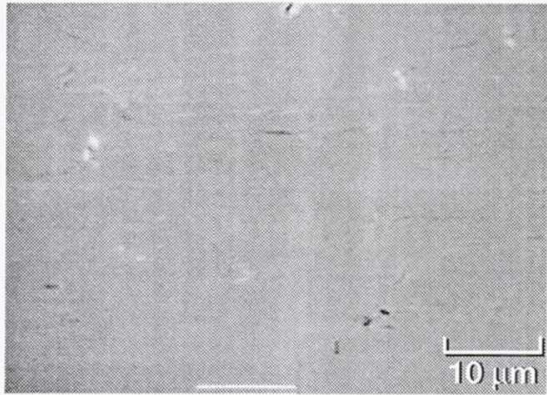

High magnification

Figure 7.33.-SEM photomicrographs of (a) wear track on synthetic singlecrystal diamond and (b) wear scar on PTFE-coated W/WC poppet.

NASA/TM-1999-107249, Chapter 7 


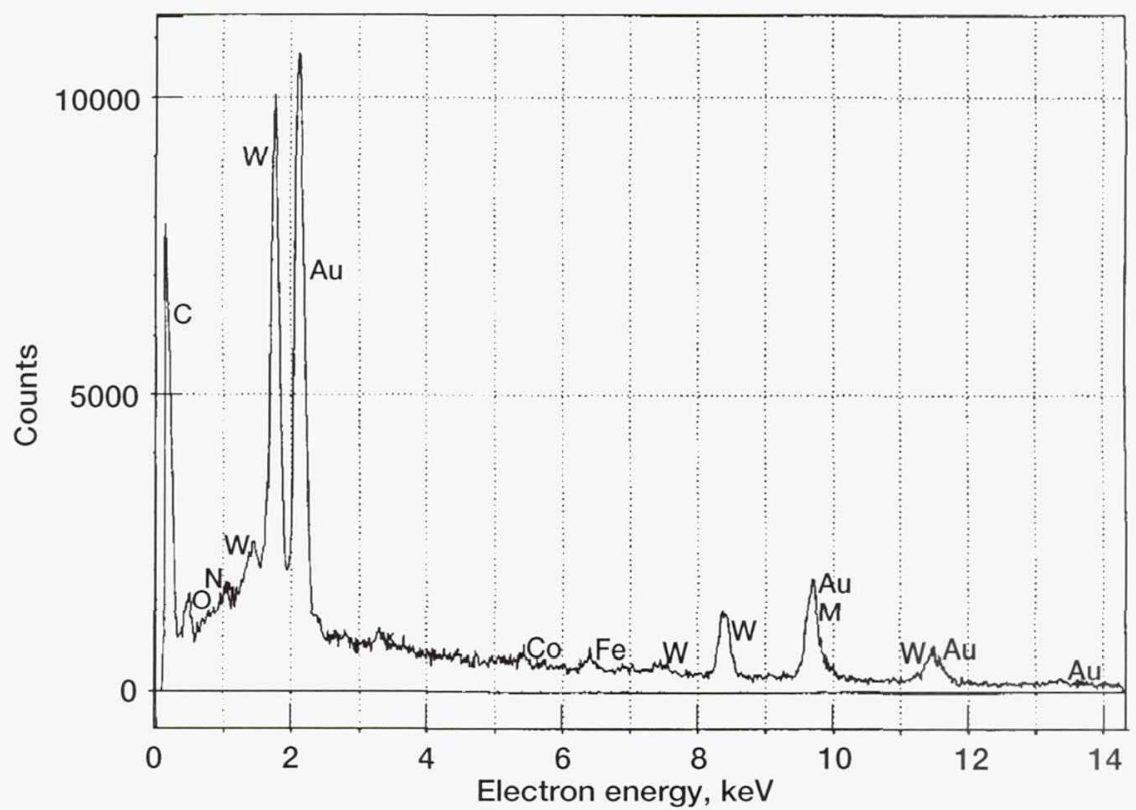

Figure 7.34.-EDX spectrum of wear track on synthetic single-crystal diamond.

produced on the PTFE-coated W/WC poppet had a smooth appearance, indicating complete removal of the PTFE coating in the observed area (Fig. 7.33(b)).

Because the natural single-crystal $\{111\}$ diamond surface was polished, it was smooth and had no cleavage steps. Figure 7.35 presents SEM photomicrographs of the wear track on the natural diamond and of the wear scar on the PTFE-coated W/WC poppet after approximately 100000 passes in air. The diamond wear track had no visible wear (Fig. 7.35(a)). Only closer SEM examination at high magnification indicated submicrometer wear debris particles from the poppet. The wear scar produced on the PTFE-coated W/WC poppet had no visible transferred material from the diamond (Fig. 7.35(b)).

Bare W/WC poppet.-Figure 7.36 presents SEM photomicrographs of the wear track on sapphire and of the wear scar on the bare W/WC poppet after approximately 53000 passes in air. The sapphire wear track contained transferred materials and wear debris. Closer SEM examination at high magnification clearly showed transferred materials from the poppet. An EDX spectrum taken at the center of the sapphire wear track indicated the presence of tungsten from the counterpart material. The wear scar produced on the bare $\mathrm{W} / \mathrm{WC}$ poppet had a relatively smooth worn surface with wear debris.

Figure 7.37 presents SEM photomicrographs of the wear track on the synthetic single-crystal diamond and of the wear scar on the bare W/WC poppet after approximately 100000 passes in air. In this case the sliding direction was almost

NASA/TM-1999-107249, Chapter 7 

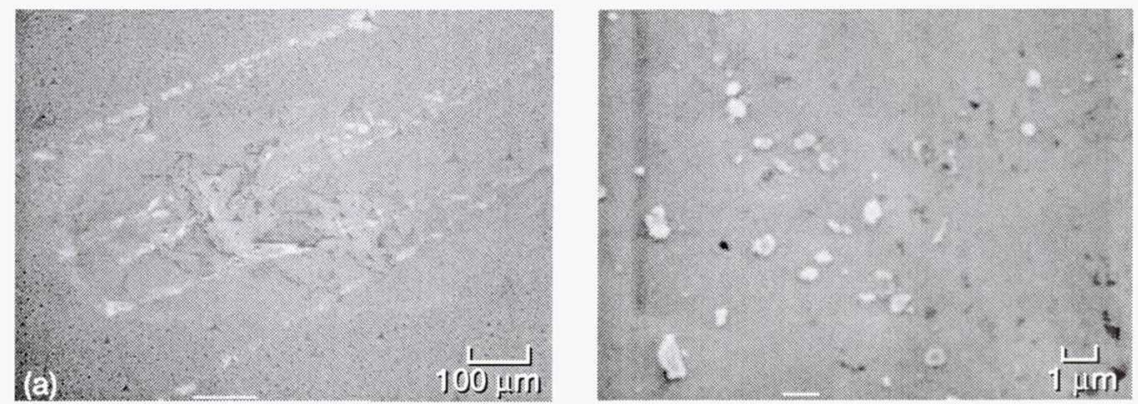

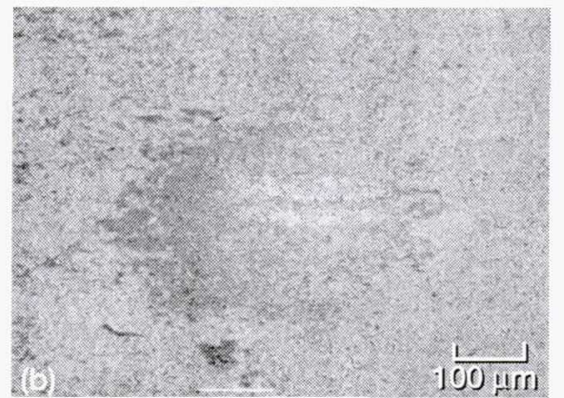

Overview

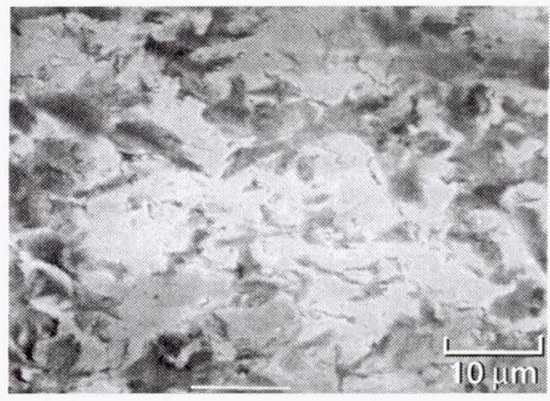

High magnification

Figure 7.35.-SEM photomicrographs of (a) wear track on natural single-crystal diamond and (b) wear scar on PTFE-coated W/WC poppet.

parallel to the cleavage steps on the diamond surface. The diamond wear track contained wear debris particles and patches of material from the poppet (Fig. 7.37(a)). An EDX spectrum taken at the patches on the diamond wear track indicated the presence of tungsten from the poppet materials. On the other hand, the wear scar produced on the bare W/WC poppet had a smooth appearance with local fracture pits (Fig. 7.37(b)).

The polished natural single-crystal diamond had no visible wear even after approximately 100000 sliding passes against the bare W/WC poppet. The bare W/WC poppet had a wear scar with wear debris, as shown in Fig. 7.38.

\subsubsection{Summary of Results and Conclusions for Case Study B}

In the investigation of failures of the space shuttle orbiter's quad check valve, the following results were obtained:

1. The coefficients of friction for a sapphire guide pin in sliding contact with both a polytetrafluoroethylene (PTFE)-coated and a bare tungsten/tungsten carbide (W/WC) poppet were high, unstable, and erratic with stick-slip behavior.

NASA/TM-1999-107249, Chapter 7 

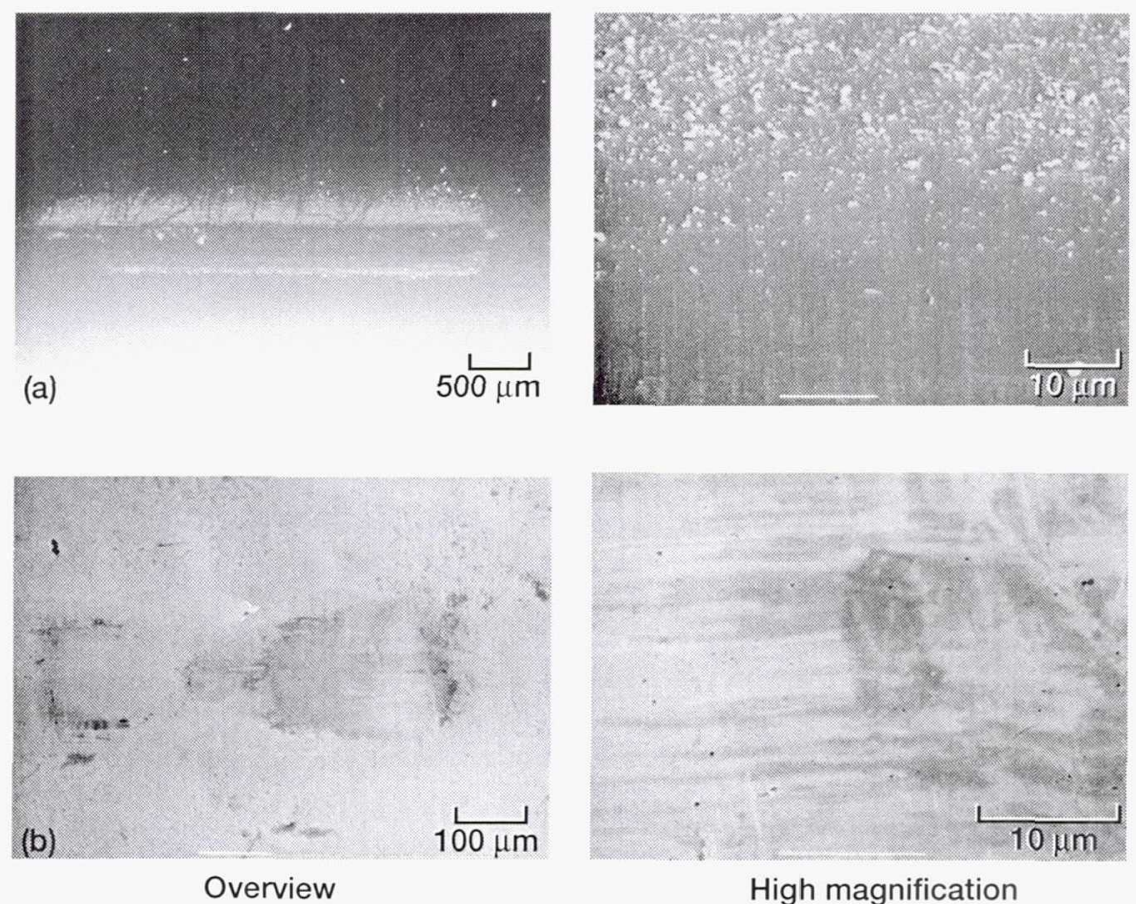

High magnification

Figure 7.36.-SEM photomicrographs of (a) wear track on sapphire and (b) wear scar on PTFE-coated W/WC poppet.
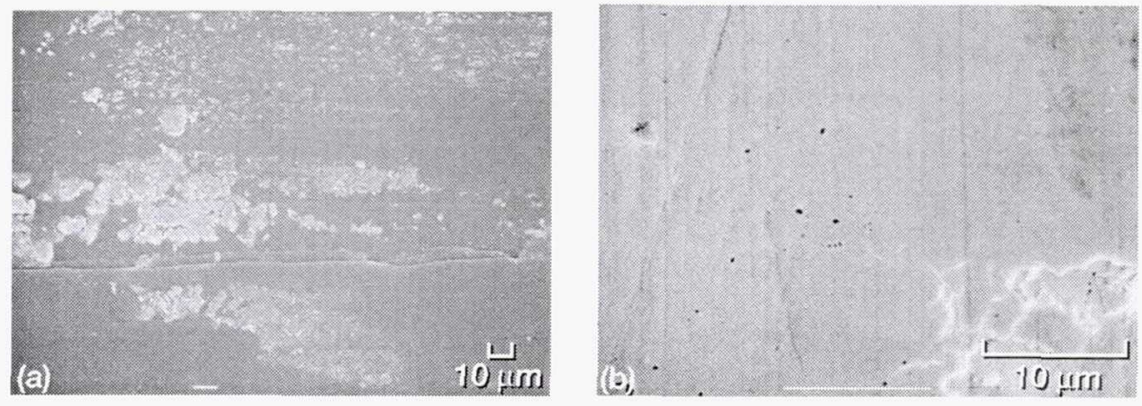

Figure 7.37.-SEM photomicrographs of (a) wear track on synthetic singlecrystal diamond and (b) wear scar on PTFE-coated W/WC poppet.

NASA/TM-1999-107249, Chapter 7 


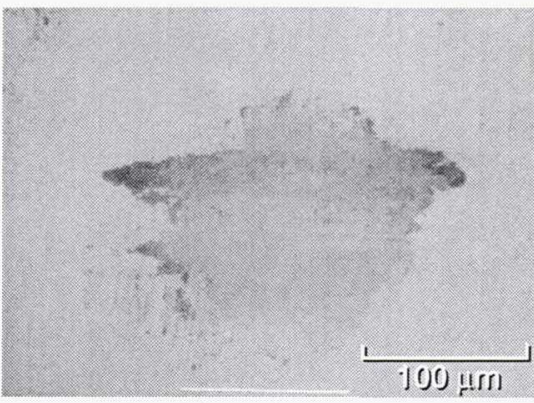

Overview

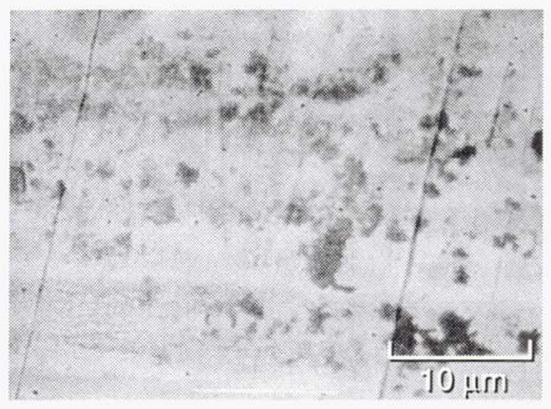

High magnification

Figure 7.38.-SEM photomicrographs of wear scar on bare W/WC poppet after sliding against synthetic single-crystal diamond.

Because of the wide variation in coefficient of friction resulting from high adhesion, it will be difficult to predict the functional performance of a check valve based on a W/WC poppet sliding on a sapphire guide pin.

2. The coefficients of friction of synthetic and natural diamond surfaces in contact with both a PTFE-coated and a bare W/WC poppet were generally low and did not show variable, stick-slip behavior. The steady-state coefficients of friction were lower for diamond sliding against the bare poppet than for diamond sliding against the PTFE-coated poppet. When compared with the sapphire guide pins the synthetic and natural diamonds reduced the coefficient of friction by factors of 4 to 8 and 35 when sliding against the PTFE-coated and bare poppets, respectively.

3. More wear debris transferred to the sapphire for the PTFE-coated W/WC poppet in sliding contact with the sapphire guide pin than for the bare W/WC poppet and sapphire couple.

4. Cleaved surfaces of synthetic diamond produced a great amount of wear debris from the poppet by cutting and plowing the sharp edges of the cleavage steps.

5. Polished surfaces of natural diamond had no visible wear and reduced poppet wear when compared with sapphire and cleaved synthetic diamond surfaces.

From these results the following conclusions were drawn:

1. The coefficient of friction for the sapphire guide pin is too high and dependent on surface conditions and would make the operation of a quad check valve (QCV) very difficult.

2. Diamond has a low and constant coefficient of friction with no stick-slip behavior. It can be effectively used as a guide pin material and can be a good replacement material for sapphire in space shuttle QCV's.

3. The sliding surface of diamond must be prepared with care. Surface integrity and smoothness are of paramount importance to functional reliability of the poppet-pin system.

NASA/TM-1999-107249, Chapter 7 


\section{References}

7.1 W. Shapiro, et al., Space mechanisms lessons learned study, Vol. I, Summary, NASA TM-107046, 1995

7.2 H.P. Jost, Tribology — origin and future, Wear, 136: 1-17 (1990).

7.3 J. Wilson, Galileo's antenna: the anomaly at 37 million miles, JPL Universe, Jet Propulsion Laboratory, July 3, 1992.

7.4 Unfurling the HGA's enigma, Galileo Messenger, Jet Propulsion Laboratory, Aug. 1991.

7.5 M.R. Johnson, The Galileo high gain antenna deployment anomaly, 28th Aerospace Mechanisms Symposium, NASA CP-3260, 1994, pp. 359-377.

7.6 K. Miyoshi, et al., Properties data for opening Galileo's partially unfurled main antenna, NASA TM-105355, 1992.

NASA/TM-1999-107249, Chapter 7 
Public reporting burden for this collection of information is estimated to average 1 hour per response, including the time for reviewing instructions, searching existing data sources, gathering and maintaining the data needed, and completing and reviewing the collection of information. Send comments regarding this burden estimate or any other aspect of this collection of information, including suggestions for reducing this burden, to Washington Headquarters Services, Directorate for Information Operations and Reports, 1215 Jefferson Davis Highway, Suite 1204, Arlington, VA 22202-4302, and to the Office of Management and Budget, Paperwork Reduction Project (0704-0188), Washington, DC 20503.
1. AGENCY USE ONLY (Leave blank)
2. REPORT DATE 3. REPORT TYPE AND DATES COVERED
August 1999
Technical Memorandum

4. TITLE AND SUBTITLE

5. FUNDING NUMBERS

Aerospace Mechanisms and Tribology Technology: Case Studies

6. AUTHOR(S)

Kazuhisa Miyoshi

7. PERFORMING ORGANIZATION NAME(S) AND ADDRESS(ES)

National Aeronautics and Space Administration

John H. Glenn Research Center at Lewis Field

Cleveland, Ohio 44135-3191

WU-523-22-13-00

9. SPONSORING/MONITORING AGENCY NAME(S) AND ADDRESS(ES)
National Aeronautics and Space Administration

9. SPONSORING/MONITORING AGENCY NAME(S) AND ADD
National Aeronautics and Space Administration

Washington, DC 20546-0001

8. PERFORMING ORGANIZATION REPORT NUMBER

E-9863-7

11. SUPPLEMENTARY NOTES

Responsible person, Kazuhisa Miyoshi, organization code 5140, (216) 433-6078.

12a. DISTRIBUTION/AVAILABILITY STATEMENT 12b. DISTRIBUTION CODE

Unclassified - Unlimited

Subject Category: 27

Distribution: Nonstandard

This publication is available from the NASA Center for AeroSpace Information, (301) 621-0390.

13. ABSTRACT (Maximum 200 words)

This chapter focuses attention on tribology technology practice related to vacuum tribology and space tribology. Two case studies describe aspects of real problems in sufficient detail for the engineer and the scientist to understand the tribological situations and the failures. The nature of the problems is analyzed and the range of potential solutions is evaluated. Courses of action are recommended.

\begin{tabular}{|c|c|c|c|}
\hline 14. SUBJECT TERMS & \multicolumn{2}{|c|}{ Solid lubrication; Coatings; Tribology fundamentals; Applications } & $\begin{array}{c}\text { 15. NUMBER OF PAGES } \\
47 \\
\end{array}$ \\
\hline NSN 7540-01-280-5500 & & & $\begin{array}{l}\text { andard Form } 298 \text { (Rev. 2-89) } \\
\text { scribed by ANSI Std. Z39-18 } \\
3-102\end{array}$ \\
\hline
\end{tabular}

